\title{
AVALIAÇÃO DO ESTADO NUTRICIONAL E DA FERTILIDADE DO SOLO NA CULTURA DO PLÁTANO (Musa AAB SUBGRUPO PLÁTANO cv. HÁRTON)
}

\section{VIANEL DE JESÚS RODRÍGUEZ PÉREZ}

\author{
Tese apresentada à Escola Superior de Agricultura \\ "Luiz de Queiroz", Universidade de São Paulo, para \\ obtenção do título de Doutor em Agronomia, Área de \\ Concentração: Fitotecnia.
}

P I R A C I C A B A

Estado de São Paulo - Brasil

Abril - 2003 


\title{
AVALIAÇÃO DO ESTADO NUTRICIONAL E DA FERTILIDADE DO SOLO NA CULTURA DO PLÁTANO (Musa AAB SUBGRUPO PLÁTANO cv. HÁRTON)
}

\section{VIANEL DE JESÚS RODRÍGUEZ PÉREZ}

Engenheiro Agrônomo

\author{
Orientador: Prof. Dr. EURÍPEDES MALAVOLTA
}

Co-orientador: Prof. Dr. JOÃO ALEXIO SCARPARE FILHO

\footnotetext{
Tese apresentada à Escola Superior de Agricultura "Luiz de Queiroz", Universidade de São Paulo, para obtenção do título de Doutor em Agronomia, Área de Concentração: Fitotecnia.
}

P I R A C I C A B A

Estado de São Paulo - Brasil

Abril - 2003 
Dados Internacionais de Catalogação na Publicação (CIP) DIVISÃO DE BIBLIOTECA E DOCUMENTAÇÃO - ESALQ/USP

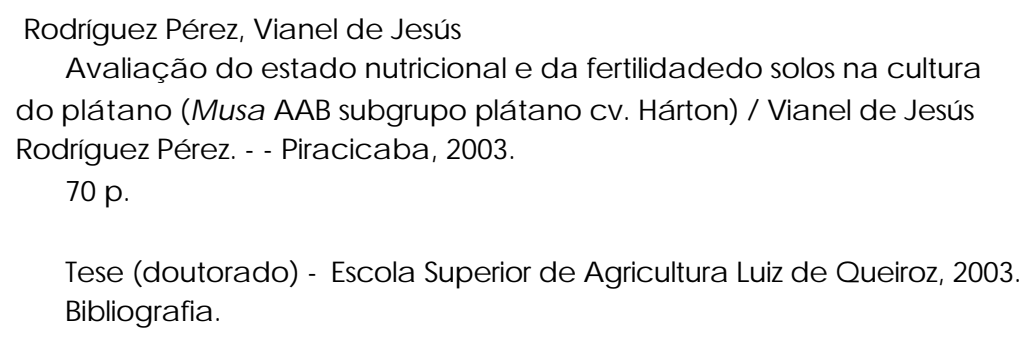

Tese (doutorado) - Escola Superior de Agric ultura Luiz de Queiroz, 2003. Bibliografia.

1. Avalia ção nutriciona I 2. Fertilida de do solo 3. Plá ta no I. Título

CDD 634.973394 


\section{Dedicatória}

Aos que realmente

promovem o progresso.

A meu pai José R. C. 


\section{AGRADECIMENTOS}

À Universidade de São Paulo, Escola Superior de Agricultura "Luiz de Queiroz", pela oportunidade de realização do curso.

Ao FONACIT pela bolsa de estudos concedida.

À Universidade Centroccidental "Lisandro Alvarado" pela liberação e financiamento para a realização do curso.

Ao CDCHT-UCLA pelo financiamento dos análises foliares e de solos.

Ao Prof. Dr. Eurípides Malavolta pela orientação, ensinamentos e apoio.

Ao Prof. Orlando A. Rodríguez R. pela amizade, incentivo e construtivas críticas.

À Profa. Aymara Sánchez pela solidariedade, apoio e parceria no laboratório para a condição criada para concretização deste trabalho.

A Hermes Rosales e Carlos Gómez, da Subestação Chama, pela seriedade na condução da coleta dos dados deste trabalho. 
A minha mamãe pelas orações e a meu irmão Leonel Rodríguez P. pelas correrias do dia a dia.

Muito especial e com gratidão a meus filhos Jesús e Vianel por aceitar incondicionalmente os retos de se afastar de nosso pais.

A minha esposa Elicel, especial dedicatória pelo indeclinável apoio.

Ao inesquecível povo Brasileiro, pela solidariedade do dia a dia. 


\section{SUMÁRIO}

\section{Página}

LISTA DE TABELAS

ix

RESUMO

xi

SUMMARY

Xiii

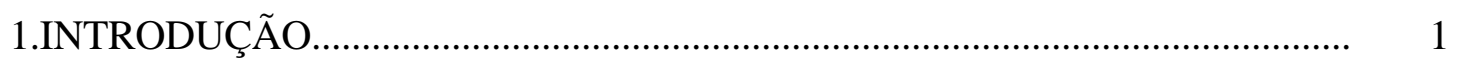

2. REVISÃO DE LITERATURA................................................................... 3

2.1 Metodologias de interpretação de análise........................................................... 3

2.2 Populações de referência...................................................................................... 4

2.3 Formas de amostragem........................................................................... 5

2.4 Tamanho da amostra............................................................................ 6

2.5 Estabelecimento ou obtenção de valores de referencia no contexto do balanço

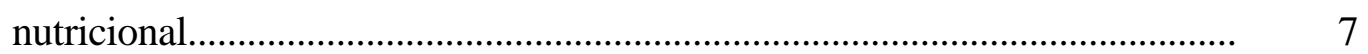

2.5.1 Obtenção dos valores de referencia como tal.................................................... 8

2.5.1.1 Valores de referencia estabelecidos através da media aritmética...................... 8

2.5.1.2 Valores de referencia estabelecidos como o ponto de inflexão em curvas de respostas..................................................................................... 9

2.5.2 Avaliação do balanço nutricional...................................................................... 9

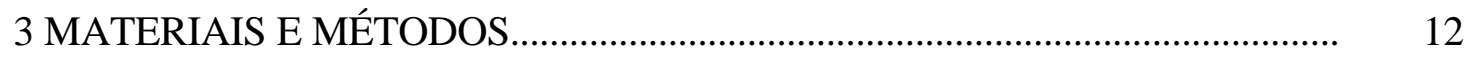




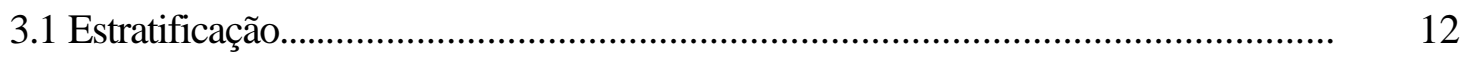

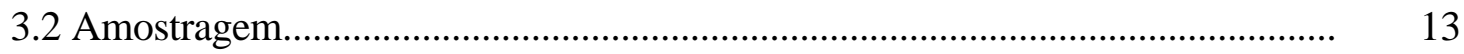

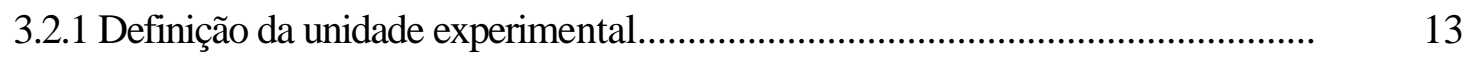

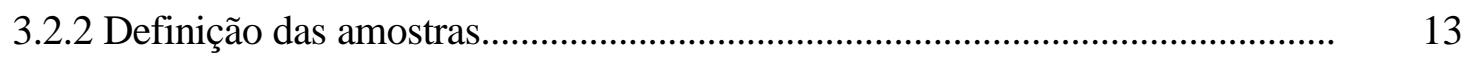

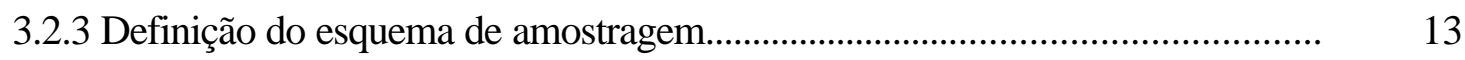

3.3 Processamento das amostras............................................................................ 13

3.3.1 Analises de laboratório............................................................................. 14

3.3.1.1 Amostras de folhas.............................................................................. 14

3.3.1.2 Amostras de solos.................................................................................. 14

3.3.2 Analise estatística....................................................................................... 15

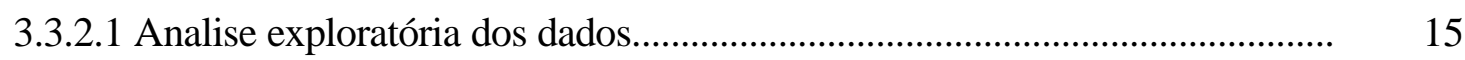

3.3.2.2 Analise de regressão por componentes principais........................................... 15

3.3.2.2.1 Determinação dos valores a ser propostos como de referência, no balanço nutricional ótimos................................................................................. 16

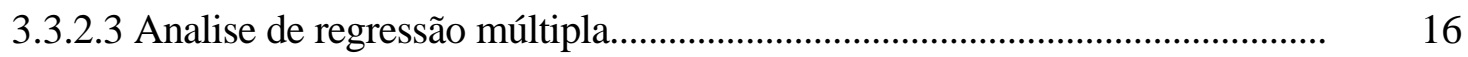

3.3.2.3.1 Determinação dos valores a ser propostos como de referência, no balanço

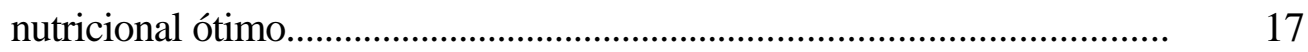

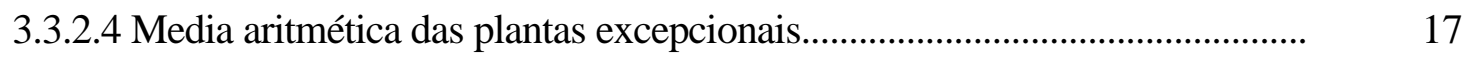

3.3.2.4.1 Determinação dos valores a ser propostos como de referencia, no balanço

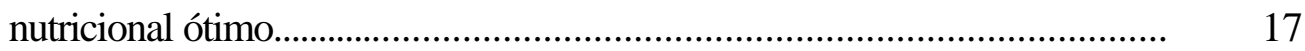

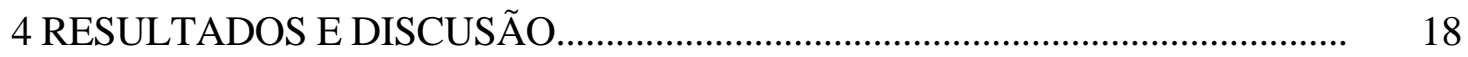

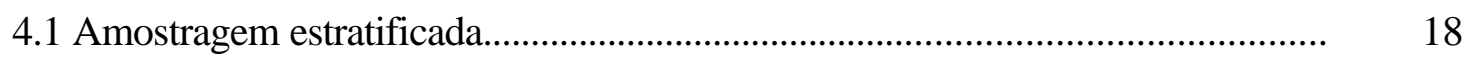

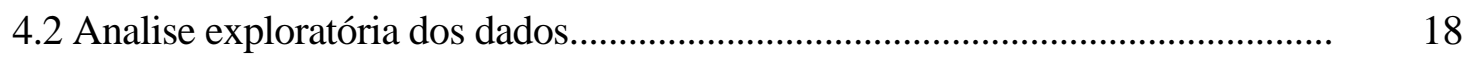

4.3 Analise de regressão por componentes principais................................................ 22

4.3.1 Balanço nutricional..................................................................................... 22

4.3.2 Determinação dos valores a ser propostos como de referencia, no balanço 


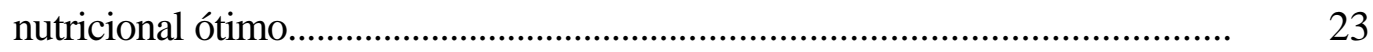

4.4 Análise de regressão múltipla........................................................................ 26

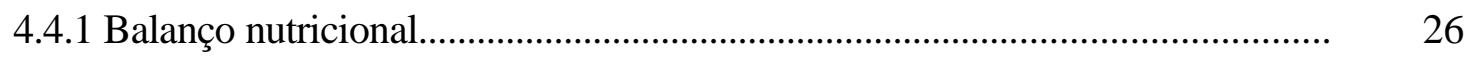

4.4.2 Determinação dos valores a ser propostos como de referencia, no balanço

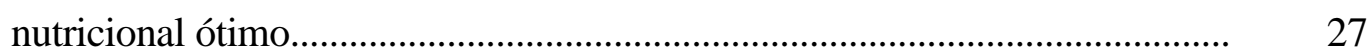

4.5 Media aritmética das plantas excepcionais...................................................... $\quad 30$

4.5.1 Balanço nutricional................................................................................ $\quad 30$

4.5.2 Determinação dos valores a ser propostos como de referencia, no balanço nutricional ótimo.......................................................................................... 33

4.6 Comparação dos valores de referência e do balanço ótimo obtido pelos três procedimentos............................................................................................ 33

4.7 Determinação da combinação ou balanço nutricional de referência........................ 37

4.8 Validação das variáveis no contexto do balanço nutricional de referência............

4.9 Quantificação do balanço nutricional..................................................................... 45

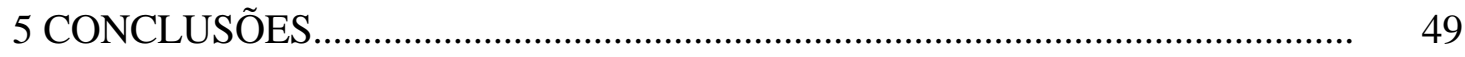

REFERÊNCIAS BIBLIOGRAFICAS............................................................. 50

ANEXO 


\section{LISTA DE TABELAS}

Página.

1 Teste de $\mathrm{t}$ para as variáveis do solo, entre as duas profundidades de amostragem: 0 - 20 e $21-40 \mathrm{~cm}$............................................................... 19

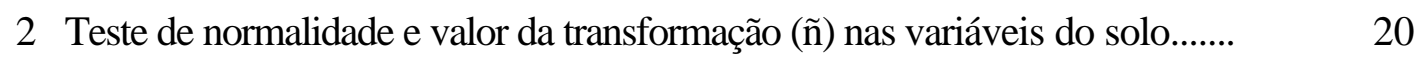

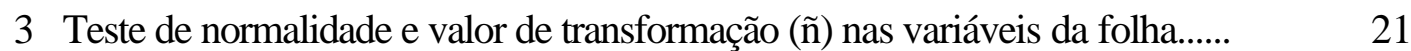

4 Coeficientes dos componentes principais (C. P.) e de cada variável do solo e da folha, nas combinações lineares associadas al rendimento........................

5 Médias aritméticas nas varáveis do solo, nas plantas acima e abaixo dos 18 $\mathrm{kg} \mathrm{cacho}^{-1}$, classificadas pelos pesos estimados por compônentes principais.

6 Medias aritméticas nas variáveis da folha, nas plantas acima e abaixo dos 18 $\mathrm{kg} \mathrm{cacho}^{-1}$, classificadas pelos pesos estimados por compônentes principais.

7 Coeficientes das variáveis que compõem o modelo de regressão múltipla entre as variáveis do solo e da folha

8 Medias aritméticas nas variáveis do solo, nas plantas acima e abaixo dos 18 $\mathrm{kg} \mathrm{cacho}^{-1}$, classificadas pelo pesos estimados por regressão múltipla............

9 Medias aritméticas nas variáveis da folha, nas plantas acima e abaixo dos 18 $\mathrm{kg} \mathrm{cacho}^{-1}$, classificadas pelo pesos estimados por regressão múltipla............

10 Medias aritméticas nas variáveis do solo, nas plantas acima e abaixo dos 18 $\mathrm{kg} \mathrm{cacho}^{-1}$, classificadas diretamente pelos pesos observados

111 Medias aritméticas nas variáveis da folhas, nas plantas acima e abaixo dos $18 \mathrm{~kg} \mathrm{cacho}^{-1}$, classificadas diretamente pelos pesos observados

12 Média da massa dos cachos nas plantas excepcionais ou $>18 \mathrm{~kg} \mathrm{cacho}^{-1}$, obtidas pelos modelos de regressão com as combinações lineares, regressão 
múltipla, por a massa ou peso observado, e ademais, novamente a massa do cacho calculada a partir dos nutrientes das mesmas plantas, pero pelos modelos de regressão múltipla (R. M.) e pelas combinações lineares (C. L.).

13 Contribuição total de cada variável do solo, nos coeficientes das combinações lineares.

14 Contribuição total de cada variável da folha, nos coeficientes das combinações lineares. 36

15 Balanço nutricional das variáveis do solo, por classes de rendimento. 38

16 Balanço nutricional das variáveis da folha, por classes de rendimento.

17 Percentagem dos nutrientes $\mathrm{K}, \mathrm{Ca}$ e $\mathrm{Mg}$, em folhas de plátano Hárton, classificadas de acordo com a massa do cacho.

18 Quocientes K/Ca e K/Mg em folhas de plátano Hárton, classificados de acordo com a massa do cacho.

19 Quociente K/Mg no solo, na cultura do plátano Hárton, classificados de acordo com a massa do cacho.

20. Quocientes K/N, N/P e K/P em folhas de plátano Hartón, classificados de acordo com a massa do cacho.

21. Quociente N/S em folhas de plátano Hartón, classificados de acordo com a massa do cacho

22 Contribuição das variáveis do solo e da folha no modelo de regressão do rendimento com as combinações lineares em: A média da subpopulação amostrada e na classe de $>20 \mathrm{~kg} \mathrm{cacho}^{-1}$ na cultura do plátano Harton 


\title{
AVALIAÇÃO DO ESTADO NUTRICIONAL E DA FERTILIDADE DO SOLO NA CULTURA DO PLÁTANO (Musa AAB SUBGRUPO PLÁTANO cv. HÁRTON)
}

\author{
Autor:VIANEL DE JESÚS RODRÍGUEZ PÉREZ \\ Orientador: Prof. Dr. EURÍPEDES MALAVOLTA \\ Co-Orientador: Prof. Dr. JOÃO ALEXIO SCARPARE FILHO
}

\section{RESUMO}

Este trabalho teve o objetivo de propor uma metodologia adequada ao diagnostico nutricional e à avaliação da fertilidade do solo, dentro do contexto do balanço nutricional da cultura do plátano (Musa AAB subgrupo plátano cv. Hárton) no Sul do Lago do Maracaibo, Venezuela. O procedimento inicial foi, estratificar a área de amostragem por series semelhantes de solos da região. Desta maneira, selecionaram-se quatro lavouras com um histórico de melhor rendimento, na serie de solos de texturas francas. Em seguida fez-se a amostragem completamente ao acaso, entre os meses de julho a dezembro dos anos 2000 e 2001. O tamanho da amostra tirada por lavoura, foi de 30 unidades experimentais. Entretanto, por segurança acrescentaram-se cerca de $25 \%$, dadas as possibilidades de perdas por rajadas de vento e chuva e outros infortúnios. A unidade experimental foi formada pela planta "mãe" e seu broto lateral "filho" em pleno desenvolvimento. Em cada unidade coletou-se a amostra foliar, na planta "mãe" de acordo a norma estabelecida pelo Método de Amostragem Internacional de Referencia (MEIR). Concomitantemente, tomou-se a amostra de solo, na faixa de 
adubação, em frente do "filho" em das profundidades $0-20 \mathrm{~cm}$ e $21-40 \mathrm{~cm}$. As amostras de folhas foram analisadas para $\mathrm{N}, \mathrm{P}, \mathrm{K}, \mathrm{Ca}, \mathrm{Mg}, \mathrm{S}, \mathrm{B}, \mathrm{Cu}, \mathrm{Fe}, \mathrm{Mn}$, Mo e $\mathrm{Zn}$. Nas amostras de solo se determinou-se $\mathrm{pH}$, condutividade elétrica, matéria orgânica, areia, silte, argila, $\mathrm{P}, \mathrm{K}, \mathrm{Ca}, \mathrm{Mg}, \mathrm{S}, \mathrm{B} \mathrm{Cu}, \mathrm{Fe}, \mathrm{Mn}$ e $\mathrm{Zn}$. Os dados foram avaliados por analises de regressão com as combinações lineares dos componentes principais, regressão múltipla e obtenção da media aritmética das plantas com maior rendimento. Os resultados demonstraram que o modelo de regressão das combinações lineares com o rendimento deu uma melhor avaliação e predição do rendimento do plátano Hárton, dentro do contexto do balanço nutricional. Com esse modelo, posteriormente estimou-se o rendimento e se separou a população em classes desde o menor até o maior rendimento. Observaram-se nos dados dos analises de solos e folhas, incrementos, decréscimos ou ausência da variação nas concentrações de nutrientes em relação com o rendimento. Isto permitiu realizar interpretações simultâneas das análises de solos e folhas sem a necessidade de valores de referência. Por conseguinte vê-se que o modelo de regressão do rendimento com as combinações lineares vai além do uso de valores de referência isolados, pois permitiu determinar e utilizar o balanço nutricional entre todas as variáveis estudadas. Os resultados assim obtidos, permitem que a metodologia utilizada, seja indicada como una proposta de interpretação dos resultados de análises de solos e folhas. 


\title{
EVALUATION OF THE NUTRITIONAL STATUS AND OF THE SOIL FERTILITY FOR THE PLANTAIN CROP (Musa AAB SUBGRUPO PLANTAIN cv. HÁRTON)
}

\author{
Author:VIANEL DE JESÚS RODRÍGUEZ PÉREZ \\ Adviser: Prof. Dr. EURÍPEDES MALAVOLTA \\ Co-adviser: Prof. Dr. JOÃO ALEXIO SCARPARE FILHO
}

\section{SUMMARY}

The aim of this work is to suggest an adequate methodology for the evaluation of the nutritional status and of the fertility of soil for plantain grown in the South of Lake Maracaibo, Venezuela. Initially the area to sample was split into similar soil series. Four high yielding plantations were selected within a soil series of intermediate texture. Afterwards a random sampling was carried out from July to December 2000 and 2001. The sample per plantation had 30 experimental units, plus $25 \%$ for safety reasons, since losses could occur due to weather conditions and other adverse factors. The experimental unit consisted of the "mother" plant and its fully developed "daughter". In each unit leaf sampling was done according to the "Method of International Sampling for Reference"(MEIR). Soil Samples were colleted in front of he daughter in the fertilization band at the depths of 0-20 and 21-40 cm. Leaf samples were analysed for $\mathrm{N}$, $\mathrm{P}, \mathrm{K}, \mathrm{Ca}, \mathrm{Mg}, \mathrm{S}, \mathrm{B}, \mathrm{Cu}, \mathrm{Fe}, \mathrm{Mn}, \mathrm{Mo}$ and $\mathrm{Zn}$. pH, conductivity, organic matter, sand, silt, clay, $\mathrm{P}, \mathrm{K}, \mathrm{Ca}, \mathrm{Mg}, \mathrm{S}, \mathrm{B}, \mathrm{Cu}, \mathrm{Fe}, \mathrm{Mn}$, and $\mathrm{Zn}$ were determined in the soil samples. Data were evaluated by regression analysis with the lineal combinations of the main 
components, and by multiple regression. Results have shown that the regression model of the lineal combination with yield gave a better evaluation and prediction of the plantain crop, within the context of nutritional balance. This, on its turn allowed for the assessment of yield and for the separation of the population in yield classes. It was possible to observe both in the soils and leaves concentrations of nutrients related and not related to yield. It was possible, therefore, to conduct simultaneous interpretation of soil and leaf analyses obviating the need for reference values. The model of regression of yield against lineal combinations goes farther the than the isolated reference values since it allowed for the determination and utilization of nutritional balance among all variables. This methodology could be proposed for the interpretation of the results of soil and plant analyses. 


\section{INTRODUÇÃO}

A industria plataneira venezuelana é conduzida por métodos tradicionais e tem tido poucas oportunidades de reorientação. No século passado, o grande cambio foi a troca da cultura do plátano Dominico pelo plátano Hárton de hoje em dia. Na década dos noventa, o aparecimento da Sigatoka Negra, foi o evento que inicio a transformação da industria (Nava, 1997), exigindo tratos culturais cada vez mais variados, adaptados ou gerados na mesma região, que aumentaram os custos e indicaram a necessidade de melhorar o desempenho dos existentes, entre eles o diagnostico nutricional e avaliação da fertilidade do solo para recomendação de adubos.

Poucos trabalhos exploram o diagnostico nutricional (Rodríguez \& Rodríguez, 1997) e o balanço nutricional (Rodríguez, et al., 1999) e menos ainda, os relacionados com a avaliação da fertilidade do solo na cultura do plátano Hárton, temas que se pretendem explorar com este trabalho.

Em geral, o fundamento do diagnostico da nutrição mineral de plantas tem base na complexidade do balanço da composição mineral do tecido, a qual é geralmente representada pela seguinte equação (Malavolta et al., 1997; Failla et al., 1997):

$\mathrm{Y}=\mathrm{f}(\mathrm{Pl}, \mathrm{S}, \mathrm{Cl}, \mathrm{Pc}, \mathrm{Pe}$

$\mathrm{Y}=$ Composição mineral da folha

$\mathrm{Pl}=$ Planta (espécie, cultivar, porta-enxerto, idade, etc)

$\mathrm{S}=$ Solo, adubação, calagem, gessagem .

$\mathrm{Cl}=$ Condições climáticas.

$\mathrm{Pc}=$ Praticas culturais

Pe $=$ Pragas e doenças

Comumente é resumida da seguinte forma: 
$\mathrm{Y}=\mathrm{f}(\mathrm{S})$

Interpretando-se de esta maneira, que o diagnostico foliar propriamente dito consiste na análise do solo usando a planta como solução extratora. Portanto: a diagnose foliar é um método para avaliação do estado nutricional e, por meio dele, a fertilidade do solo e as necessidades de adubos dentro de critérios econômicos (Malavolta, 1999), semelhante ao que se faz diretamente com a analises de solos, em relação a fertilidade.

Para atingir esses objetivos, devem-se obedecer os princípios de reprodutibilidade, operacionalidade e incerteza e cumprir as etapas de calibração (Relação entre nutrientes e a produção) e a comprovação (Malavolta, 1999).

Por esta razão, na elaboração de metodologias de interpretação de análise, os princípios são fundamentais no processo de seleção da população a ser referência, surgindo a convenção que a população deve representar acertadamente, em cada uns de seus valores da composição mineral das folhas e do solo, as condições ecofisiológicas e as correlações com o rendimento.

Essa representação e a confiabilidade da composição mineral é exigente na criação de bancos de dados por região, tipo de solo, diferentes épocas (seca e chuvosa) e por variedades. É possível o agrupamento de diferentes bancos de dados, sempre que exista compatibilidade entre eles. Quanto mais especifico for o banco de dados, maior é a probabilidade de obter uma interpretação confiável (Gallo et al., 1972; Evanylo et al., 1987; Righetti et al. 1988a, 1988b; Parent \& Granger, 1989; Bataglia \& Santos, 1990; Leandro et al., 1999; Sumner, 1999; Reis, 2002).

Por isso, o objetivo do presente trabalho, é propor uma metodologia adequada ao diagnostico nutricional da planta e a avaliação da fertilidade do solo, no contexto do balanço nutricional da cultura do plátano Hárton no Sul do Lago do Maracaibo, Venezuela. 


\section{REVISÃO DE LITERATURA}

\subsection{Metodologias de interpretação de análise}

O ponto crítico na implementação de qualquer sistema de interpretação ou diagnostico foliar é o estabelecimento dos valores de referência (Prevot \& Ollagnier, 1957; Holland, 1966; Bates, 1971; Walworth \& Sumner, 1987; Lucena, 1997). Sem referência não se pode fazer a interpretação.

No caso do diagnostico foliar, ele pode ser feito utilizando como valores de referência os quocientes: nutriente com a matéria seca e nutriente com outro nutriente.

O uso do quociente, nutriente com a matéria seca, é representado pelo nível crítico (Macy, 1936; Clark \& Powers, 1945; Ulrich, 1952; Prevot \& Ollagnier, 1957), nível critico inferior ou nível critico fisiológico (Malavolta et al., 1997). Variantes para melhorar este conceito são: patamar do nível crítico (Melsted et al., 1969; Dow \& Roberts, 1982), e o nível critico fisio-económico (Malavolta et al., 1997).

Por outro lado, o uso do quociente entre nutrientes, com dois elementos, é representado pela técnica "Diagnostic Physiologique", a qual foi proposta por Beaufils (1957), técnica que deu base ao DRIS (Diagnosis and Recommendation Integrated System) (Beaufils, 1973, 1976) para a interpretação de análise de folhas e de solos (Oliveira, 1999), ao igual que a relação entre três elementos proposta por Lagatu \& Maume feita em 1926 (Holland, 1966), na técnica denominada "Diagnostic Foliare".

Propostas de metodologias de interpretação de análises abrangendo todos os elementos, atualmente estão representados por: DRIS através dos índices dos nutrientes (ID-DRIS) (Beaufils, 1973) e os índices de balanço dos nutrientes-DRIS (IBN-DRIS) 
(Sumner, 1977a; 1977d), os índices de balanço DOP (Deviation from Optimum Percentage) (Monge et al., 1995; Montañez et al., 1995; Sanz et al., 1999), os conceitos de CND (Compositional Nutrient Diagnosis) (Parent \& Dafir, 1992; Parent et al., 1993; Parent et al., 1994a; Parent et al., 1994b; Parent et al., 1995) e por PCA (Principal components analysis) (Holland, 1966; Ovalles \& Collins, 1988; Delvaux, 1995).

Convem lembrar que quando foram desenvolvidos para dois, três ou todos os elementos, as propostas envolveram a importância fundamental dos quocientes entre elementos visando o equilíbrio nutricional, visto que os nutrientes nas folhas e no solo não são independentes uns de outro, dado que interatuam em um balanço complexo e dinâmico.

\subsection{Populações de referência}

$\mathrm{Na}$ seqüência da interpretação dos análises de folhas e solos, os valores de referência são obtidos em populações a ser consideradas como tal.

Sua acertada seleção é fundamental no sucesso e eficiência da interpretação.

Estas populações podem ser indivíduos dos estudos controlados em estações experimentais e/ou obtidas nas melhores lavouras.

Com experimentos e delineamentos apropriados, alem do ajuste dos modelos mais adequados, tem-se estimativas não enviesadas dos parâmetros de resposta (Nelson, 1999) a ser estabelecidos como valores de referência.

Esta alternativa requer anos de trabalho, que não se ajusta á necessidades da avaliação da fertilidade e nutrição de plantas em áreas novas, culturas ou híbridos novos e/ou estratégias de culturas em médios de sustentação diferentes ao solo.

Por esta razão, Marchal et al. (1972); Beaufils (1973, 1976), Delvaux et al. (1986), Delvaux et al. (1990), Dorel \& Perrier (1990), Lahav (1995), Delvaux (1995), Failla et al. (1997), fazem a proposta da formação de populações de referência ou bancos de datos através do inventario, pesquisa ou revisão bibliográfica de todos os dados disponíveis das atividades dos agricultores e/ou das condições experimentais. 
Nesta proposta, o principal objetivo é determinar a influencia das condições edafoclimáticas e tratos culturais no potencial de rendimento numa cultura (Delvaux, 1995).

A formação de bancos por inventario disponibilizam a possibilidade de comparar diferentes condições de solos e clima num virtual arranjo experimental multilocais que poderiam demonstrar o efeito de tratos culturais sob diversos solos (Delvaux, 1996).

Alternativa originalmente difundida, se baseou na extração e processamento da informação dos dados já existentes (Beaufils, 1973; Sumner, 1977 a; 1977b; 1977c; Amundson \& Koehler, 1987; Evanylo et al., 1987; Mackay et al., 1987; Walworth \& Sumner, 1987; Bataglia, 1989; Angeles et al., 1990; Hallmark et al., 1990; Savoy \& Robinson, 1990; Jones \& Sinclair, 1991; Goh \& Malakouti, 1992; Angeles et al., 1993; Cadwell et al., 1994; Bell et al., 1995; Raghupathi et al., 2002). O conjunto de dados geralmente é proveniente de experimentos sob condições controladas, com observações aleatoriamente distribuídas e associadas ao rendimento.

Entretanto nas culturas e/ou áreas novas, dentro da qual se tem de pouca ou nenhuma informação, o amostragem da população surge como uma alternativa confiável (Cochran, 1965; Esteban \& Aguilar, 1976; Langenegger \& Du Plessis, 1977; Delvaux et al., 1986; Bataglia, 1989; Hockman et al., 1989; Lozano \& Huynh, 1989; Bataglia \& Santos, 1990; Bowen, 1990; Szücs \& Kallay, 1990; Dara et al., 1992; Goh \& Malakouti, 1992; Adetunji, 1994; Parent et al., 1995; Failla et al., 1997; Awasthi et al., 1998; Raghupathi et al., 2002).

A alternativa exige um conhecimento claro de seus princípios para sua impecável aplicação. A amostra é boa quando se está seguro de que se tomou a amostra corretamente.

\subsection{Formas de amostragem}

Uma área pode ser avaliada usando técnicas particulares de amostragem que possam estimar o nível médio de cada nutriente e a dispersão (variância) de toda o área. As recomendações para uma lavoura que não esta entre as lavouras que foram amostradas é baseada na média aritmética para toda a área e de qualquer outra 
informação sobre o trato cultural passado e as diferenças particulares da primeira (Nelson, 1999).

Ao tomar uma amostra de tamanho $n$ de uma população $N$, pode-se estimar a média ( ì ) e a variância (2)ó da população. Estes parâmetros descrevem bem uma distribuição, especialmente a distribuição normal (Nelson, 1999).

Infelizmente, poucos dados da composição mineral dos tecidos e do solo estão normalmente distribuídos (Walworth \& Sumner, 1987; Szücs, et al., 1990; Schaller et al., 1995), precisando-se de apropriadas transformações (Holland, 1966; Holland, 1969; Beverly, 1987a; 1987b; Parent \& Dafir, 1992), e ainda assim, tem-se dificuldade em obter a normalidade da distribuição em populações muito heterogêneas.

Haynes em 1948, citado por Fitts \& Nelson (1956), assinalou que em populações muito heterogêneas, o melhor método é a amostragem estratificada, seguido pelo zigzag, particularmente a níveis de amostragem muito baixos. Nelson (1999) estabelece que a vantagem da estratificação é que baixa a variância e aumenta a precisão.

Os principais tipos de solos (Cline, 1944, Evanylo et al., 1987) ou as diferenças de manejo justificam a estratificação.

\subsection{Tamanho da amostra}

Ao realizar um estudo por amostragem, um dos aspectos mais importantes é determinar o tamanho da amostra que será usada quando se quer estimar alguns dos parâmetros da população (Alvarez, 1988).

A subpopulação deve coincidir com a população da qual se desejam as informações (população objetivo). Qualquer informação complementar, que poda ser recolhida com respeito á natureza das possíveis diferenças entre a sub-população da amostra e a população objetivo, pode ser útil na interpretação dos dados (Cochran, 1965).

Quando é associada a precisão e o tamanho desejável, a precisão da média da amostra $(\overline{\mathrm{X}})$ aumenta na medida que cresce o tamanho da amostra e essa precisão 
dependerá de quanto o pesquisador deseja ou permitirá que a estimativa e o parâmetro, se afastem (Alvarez, 1988; Nelson, 1999).

A média da amostra se aproxima da distribuição normal na medida que aumenta o tamanho daquela, sem tomar em conta a forma da população que esta em estudo. Isto se explica pela teoria do Limite Central. Uma amostragem de 30 indivíduos (Delvaux et al., 1986), segundo Nelson (1999) é bastante grande como para assegurar uma adequada aproximação á distribuição normal (enquanto, pode ser necessário mais de 30 individuos para lograr a precisão desejada). Para que esta relação se conserve admite-se que a variância é finita e a amostra foi tomada ao azar (Nelson, 1999).

Na pratica, quanto mais simétrica ou próxima da normalidade estiver a distrbuição da população , menor a necessidade de amostras muito grandes e, em muitos casos, uma de 4 a 5 elementos já é suficiente (Costa Neto, 1999).

\subsection{Estabelecimento ou obtenção de valores de referência no contexto do balanço nutricional}

Em geral, os valores de referência podem ser estabelecidos das maneiras seguintes:

1. Através de experimentos em campo, onde se determinam as resposta á aplicação de adubos (Wood , 1980; Mamaril, 1985; Nelson, 1999), seja no rendimento ou no teor no tecido.

2. Plantas crescendo em condições hidropônicas, que implica controladas condições nutricionais e ambientais (Lucena, 1997).

3. Analises estatísticas de numerosos dados, proveniente de populações de alto rendimento (Reuter \& Robinson, 1988; Lucena, 1997).

Pela natureza da operação matemática utilizada, os valores dos nutrimentos a ser considerados como referência obtêm-se através de dois grandes critérios:

1. Valores de referência estabelecidos através da média aritmética, e

2. Valores de referência estabelecidos no ponto de inflexão das curvas de resposta. 
No critério 1, acredita-se que nas médias aritméticas obtidas, nas populações experimentais, seja qual fora o procedimento aplicado como se explica o itens 2.5.1.1, correspondem ao balanço nutricional desejável, podendo-se fazer diagnósticos posteriores confiáveis, com as diversas metodologias, discutidas no itens 2.5.2.

A média não é sempre uma boa estimativa do balanço nutricional, visto que cada valor da média é obtido independentemente, sem indicação do balanço ideal entre todos os nutrientes.

No critério 2, tem-se uma semelhança ao balanço nutricional , avaliações feitas com regressão linear múltipla. Calcula-se a variável dependente (y) (geralmente o rendimento) em função de duas ou mais variáveis nddependentes $\left(\mathrm{x}_{\mathrm{i}}\right)$. Admite-se que (y) varie linearmente com as variáveis $\left(\mathrm{x}_{\mathrm{i}}\right)$, de maneira conjunta, em sua relação funcional.

Entretanto, as variáveis onde não existe uma relação funcional ficam fora do modelo de regressão, do mesmo modo que a possibilidade de avaliar sua contribuição no balanço nutricional.

\subsubsection{Obtenção dos valores de referência como tal}

\subsubsection{Valores de referência estabelecidos através da média aritmética}

Parte-se do principio na qual, a média aritmética ao ser estimada em grupos de plantas excepcionais, dada a distribuição normal das observações, permite obter uma estimativa dos valores do elemento a ser considerados de referência.

Neste critério podem ser selecionados todos ou só alguns dos nutrientes.

No primeiro caso, a seleção atinge todas as combinações possíveis entre os nutrientes estudados, as quais apresentam a maior razão de variância entre a população de menor e mais alto rendimento, que sejam ou não estatisticamente diferentes (Jones, 1981; Angeles, et al.,1990; Savoy \& Robinson, 1990; Szücs \& Kállay, 1990; Rafthon \& Burger, 1991; Sánchez et al., 1991; Arnold et al., 1992; Dara et al., 1992; Malavolta, et al., 1993; Angeles, et al.,1993; Cerdá et al., 1995; Creste, 1996; Malavolta et al. 1997; 
Rodríguez \& Rodríguez, 1997; Rodríguez et al., 1997; Raghupathi \& Bhargava, 1999; Awasthi et al. 2000; Singh et al., 2000).

No segundo caso, a seleção só atinge os nutrientes cujas médias e variâncias sejam estatisticamente diferentes (Alkoshab et al., 1988), ou simplesmente as médias, aos níveis de probabilidade do 0,01, 0,05 ou 0,1 (Rossi, 1976; Jones, 1981; Caron \& Parent, 1989; Hockman et al., 1989; Lozano \& Huynh, 1989; Needham et al., 1990; Caron et al., 1991; Rafthon \& Burger, 1991; Beverly \& Worley, 1992; Hamel et al., 1992; Malakouti, 1992; Wortmann et al., 1992; Navvabzdeh \& Malakouti, 1993; Cadwel et al., 1994; Schaller et al., 1995; Creste \& Nakagawa, 1997; Nogueira et al., 1997; Burke \& Raynal, 1998; Hartz et al., 1998; Wadt et al. 1998a; 1998b; Wadt et al, 1999).

\subsubsection{Valores de referência estabelecidos como o ponto de inflexão em curvas de respostas}

Parte do principio que se pode obter ou estimar o rendimento ou outra variável de interesse, partindo do conhecimento de outras variáveis (geralmente um elemento). A relação entre essas variáveis é dada por uma função matemática cujos coeficientes são determinados por métodos, que estatisticamente apropriados, podem ser mais informativos e úteis (Pimentel \& Conagin, 1991; Nelson, 1999).

O valor encontrado nos modelos pode ser obtido através de níveis crescentes do elemento estudado via fertilizante, ou por inventario de populações em diferentes condições de fertilidade de solos (Szüics et al., 1990; Failla et al., 1997).

\subsubsection{Avaliação do balanço nutricional}

Diversas metodologias de interpretação de análise nos quais proponha-se avaliar o balanço nutricional, foram apresentados por Holland, 1966 através do analise dos componentes principais; Beaufils, 1973, Sumner 1977 a, 1977d, através do DRIS (Diagnosis and Recommendation Integrated System); Parent \& Dafir, 1992, através do 
CND (Compositional Nutrient Diagnosis); Schaller et al., 1995, a traves do CND-DRIS, e Montañes et al., 1995, através do DOP (Desviation from Optimum Percentage).

- A analise dos component es principais, pode ser descrita como um procedimento que transforma um conjunto de dados dentro de outros conjuntos, com certas propriedades: a) os novos conjuntos de dados são independentes uns de outros. b) há uma relação funcional linear c) a variação total do novo conjunto, equivale á variação total dos dados originais.

Estas propriedades são muito importantes porque permitem avaliar simultaneamente numerosas variáveis (tecidos, solos, etc) numa relação funcional linear (Holland, 1966), vantagem que permitiria obter o balanço ou desbalanço nutricional com distintos níveis do rendimento ou variável a avaliar.

Esta proposta exige normalidade na distribuição dos dados e utiliza a média da população como valor de referência. Esta ultima desvantagem pode ser contornada calculando a contribuição total de cada variável, dentro dos componentes principais (associados ao rendimento) na população excepcional, obtendo-se desta maneira, classificação das variáveis desde a que mais contribui para o máximo rendimento ate a que menos o faz.

- A avaliação do balanço nutricional através do DRIS, tem inicio no uso dos valores de referência estabelecidos através da média aritmética como se indica no item 2.5.1.1, sobre os quais agrupa-se em combinações binárias, para posteriormente ser padronizados (pelas funções DRIS), transformados (pelos índices DRIS) e finalmente associados ao rendimento ou outra variável através do Índice de Balaço Nutricional (IBN) para poder fazer a avaliação.

Desta maneira, quanto maior é o valor do IBN, maior será o indicio de que a planta encontra-se em desequilíbrio nutricional e, por tanto, menor será seu rendimento (Creste, 1996; Rodríguez et al., 1999; Wadt, 1999). Lamentavelmente essa relação funcional entre as duas variáveis não sempre é possível de ser explicada com una linha teórica de regressão (Bataglia et al., 2001), fazendo impossível a avaliação do balanço nutricional. 
- Por outro lado CND e CND-DRIS, fundamentam-se na teoria da analise multivariada dos dados de composição dos tecidos.

Inicia seu calculo no uso de valores de referência obtidos de populações excepcionais, sobre os quais se agrupam em combinações de multinutrientes, incluindo a matéria seca, posteriormente padroniza-os (pelos índices CND) para finalmente fazer a analise dos componentes principais.

O CND descarta informação ao acaso e conserva só componentes significativos.

Esta proposta esta limitada só à analise de tecidos.

- O DOP, como o DRIS, inicia-se com os mesmos valores de referência, que são diretamente transformados (Índices DOP) e logo associados na sumatoria DOP.

Como no DRIS, quanto maior o valor da somatória DOP, maior é a indicação de desequilíbrio nutricional, e por tanto, apresenta as mesmas desvantagens já assinaladas. 


\section{MATERIAIS E MÉTODOS}

\subsection{Estratificação}

Estabeleceram-se os estratos de acordo com a serie de solos que caracterizam ao setor rio Mucujepe-Escalante, zona sul do lago de Maracaibo, Venezuela (Kijeswski, et al., 1981). A região tem características de bosque úmido tropical, temperatura média anual de $26,8^{\circ} \mathrm{C}$, umidade relativa de $83 \%$, precipitação de 1738,4 mm e 54 m.s.n.m.

O procedimento inicialmente aplicado foi localizar as propriedades (que previamente já se sabia ter o histórico de melhores produtoras) no mapa de series de solos (Gallo et al., 1974; Delvaux et al., 1986), fazendo uma separação previa em grupos de os quais se apresentassem numa mesma serie.

Médiante esse procedimento obteve-se quatro propiedades (Anexo 1), que apresentam solos das unidades Chama \# 1 (Unidade com 41.114 ha) e Padre \# 37 (Unidade com 29.563 ha), as duas com textura predominante franca, com alta quantidade de silte.

Os restantes estratos selecionados, ficam à disposição de futuras amostragens.

Dentro do estrato selecionado, realizou-se a amostragem completamente ao acaso, entre os meses de julho a dezembro (período anual com os mais altos rendimentos) nos anos 2000 e 2001.

O tamanho da amostra, baseou-se em 30 amostras (Delvaux et al., 1986). Entretanto, visto que entre o período de amostragem e a obtenção de informação referente ao rendimento de cada unidade, transcorreram 10 semanas (como é explicado no seguinte tópico), por segurança foram agregadas um $25 \%$ a mais de cepas, dada a 
possibilidade de perdas por rajadas de vento e chuva, e outros infortúnios, muitos freqüentes na região.

\subsection{Amostragem}

\subsubsection{Definição da unidade experimental}

Foram selecionadas como unidade experimental a "touçeira" de plátano, que apresentava duas plantas, sendo a planta "mãe" no momento da emissão da inflorescência, com um brote lateral "filho" em pleno desenvolvimento.

\subsubsection{Definição das amostras}

Tomou-se a amostra foliar na planta "mãe", de acordo á normativa estabelecida pelo Método de Amostragem Internacional de Referência (MEIR) (Martin-Prével, 1980a; 1980b), concomitantemente, a amostra de solos tomou-se sobre a faixa de aplicação dos adubos, ao frente do brote lateral "filho" a duas profundidades: $0-20 \mathrm{~cm}$ e $21-40 \mathrm{~cm}$.

\subsubsection{Definição do esquema de amostragem}

Tendo em consideração que as fazendas tinham um histórico de melhores produtoras, dentro da área de plantação foi tomado ao acaso qualquer lote e estabeleceut se uma diagonal de referência para localizar as touçerias de novo na colheita. Percorrendo a diagonal foram tomadas as amostra nas plantas que reuniam as condições estabelecidas no Método de Amostragem Internacional de Referência. As plantas foram marcadas com tinta brilhante.

\section{3 Processamento das amostras}




\subsubsection{Analises de laboratório}

As amostras foram enviadas anualmente à Unidade de Investigação em Solos e Nutrição de plantas do Departamento de Química e Solos do Decanato de Agronomía da Universidade Centroccidental "Lisandro Alvarado", sediada em Tarabana, Edo. Lara, Venezuela.

Com o exceção de uma alíquota da matéria seca, a qual foi enviada para o laboratório de Química Analítica "Henrique Bergamin Filho" do Centro de Energia Nuclear na Agricultura, Piracicaba, Brasil.

\subsubsection{Amostras de folhas}

O nitrogênio e o enxofre foram determinados diretamente na matéria seca ao colocar-se no cano de combustão do forno do analisador N-S 2000. O nitrogênio foi quantificado por variação da condutividade térmica e o enxofre por absorção de infravermelho.

Os nutrientes fósforo, potássio, cálcio, magnésio, boro, cobre, ferro, manganês e zinco foram determinados no extratos da matéria seca obtida por digestão via seca (forno elétrico a $550^{\circ} \mathrm{C}$ ) até a obtenção de cinza branca.

Os fósforo e o boro foram quantificados por colorimetria do metavanadato (Malavolta et al., 1997) e colorimetria com o reagente azometina-H (Lachica, 1976; Malavolta et al. 1997), respectivamente. Entretanto, os nutrientes potássio, cálcio, magnésio, cobre, ferro, manganês e zinco por espectrofotometria de absorção atômica.

No caso do molibdênio, na preparação do extrato da matéria seca, foi obtido por digestão nitro-perclórica e a quantificação do nutriente a partir dele, foi feita pela técnica de espectofotometria de emissão atômica com plasma de argônio, ou ICP - AES (Malavolta, et al., 1997).

\subsubsection{Amostras de solos}


Os atributos: pH em água e condutividade elétrica no extrato solo-água na relação 1:2; matéria orgânica pelo método de combustão úmida com determinação do carbono orgânico por colorimetria e a analise textural pelo método de Bouyoucos.

Os nutrientes: Fósforo, pelo método Olsen, extração com solução de bicarbonato de sódio $\left(\mathrm{NHCO}_{3}\right)$ 0,5 M a pH 8,5 e determinação colorimetrica, potássio, cálcio e magnésio extraídos com acetato de amônio 1 N, pH 7,0 e a determinação do potássio por fotometria de chama e cálcio e magnésio por espectrofotometria de absorção atômica. Enxofre foi determinado por turbidimetria e o boro por colorimetría. Cobre, ferro, manganês e zinco foram extraídos com DTPA, pH 7,2 e determinados por espectrofotometria de absorção atômica.

\subsubsection{Analise estatística}

\subsubsection{Analise exploratória dos dados}

Aos dados do solo, aplicourse o teste t, entre as profundidades de amostragem, com o objetivo de determinar si existem diferenças entre as profundidades de 0-20 e 2140.

Com as profundidades definidas de acordo ao teste $\mathrm{t}$ para as variáveis do solo, procedeu-se a determinar a normalidade dos dados de solos e folhas, aplicando a prova de Shapiro \& Wilk (1965), e no caso de precisar-se foi aplicado a transformação de dados entre (-)2 a 2, de Box \& Cox (1964).

\subsubsection{Analise de regressão por componentes principais}

Antes de estabelecer o modelo, foram padronizada só as variáveis normalmente distribuídas, mediante a subtração em cada observação da média geral dividida pelo seu respectivo desvio padrão, como se indica na formula seguinte:

$$
\begin{aligned}
& \mathrm{x}_{\mathrm{ip}}=\left(\mathrm{x}_{i}-\grave{\mathrm{i}}\right) / \mathrm{o} \\
& \mathrm{x}_{\mathrm{ip}}=\text { valor padronizado }
\end{aligned}
$$


$\mathrm{x}_{i}=$ qualquer observação $\mathrm{x}_{i}$

ì = média da população

ó = desvio padrão

Esse cálculo permitiu ter as variáveis de solo e folhas numa mesma unidade, com média zero e desvio padrão 1 .

Posteriormente foram construídas combinações lineares não correlacionadas das variáveis medidas (componentes principais) do solo e folhas.

Por ultimo foi estabelecido um modelo de regressão do rendimento com as combinações lineares via método de Stepwise (Johnson \& Wichern, 1995).

\subsection{Determinação dos valores a ser propostos como de referência, no balanço nutricional ótimos}

Para obter os valores das variáveis na faixa de rendimento de acordo com seu balanço nutricional respectivo, foi dividida a sub-população em dois grupos, de acordo aos pesos estimados pelo modelo de regressão do rendimento com as combinações lineares: Plantas com massa de cacho de mais e de menos de $18 \mathrm{~kg}$ ( Haddad et al., 1994; Rodríguez \& Rodríguez. 1997).

Em seguida se procedeu ao calculo da média de cada elemento no solo e na folha em cada faixa.

\subsubsection{Analise de regressão múltipla}

Foi estabelecido um modelo de regressão linear múltipla (Rossi, 1976; Awasthi, et al., 1998) a partir das variáveis, que estivessem ou não normalmente distribuídas, pelo método de Stepwise (Beauclair, 1991; Carmello, 1991; Johnson \& Wichern, 1995). A finalidade foi a de relacionar as variáveis do solo e folhas com o rendimento e dispor assim de um modelo matemático que possa determinar o balanço ideal da concentração dos nutrientes, ou valor do atributo no solo, para um determinado rendimento da cultura. 


\subsection{Determinação dos valores a ser propostos como de referência, no balanço nutricional ótimo}

Em seguida foi dividida a sub-população de amostragem em dois grupos, de acordo aos pesos estimados pelo modelo de regressão linear múltipla: Plantas com massa de cacho de mais e de menos de $18 \mathrm{~kg}$ (Haddad et al., 1994; Rodríguez \& Rodríguez. 1997).

E finalmente se procedeu ao calculo da média de cada elemento em solos e na folha em cada faixa.

\subsubsection{Média aritmética das plantas excepcionais}

Foram utilizandas todas as variáveis, estivessem ou não com distribuição normal, sem nenhum calculo adicional do que foi feito pelo teste $t$ e a transformação das variáveis.

A subpopulação de amostragem foi dividida em dois grupos, desta vez, de acordo aos pesos observados ou obtidos na lavoura, em: Plantas com massa de cacho de mais e de menos de $18 \mathrm{~kg}$ (Gallo et al., 1974; Letzsch \& Sumner, 1984; Angeles et al., 1990; Angeles et al., 1993; Rodríguez \& Rodríguez. 1997).

Em seguida se procedeu ao calculo da média de cada elemento no solo e na folha em cada faixa.

\subsection{Determinação dos valores a ser propostos como de referência, no balanço nutricional ótimo}

Em principio assume-se que as médias na faixa de mais de $18 \mathrm{~kg}$ cacho $^{-1}$ correspondem ao balanço nutricional ótimo. 


\section{RESULTADOS E DISCUSÃO}

\subsection{Amostragem estratificada}

Os resultados obtidos, provenientes da amostragem das lavouras, encontram-se no anexo A.

\subsection{Analise exploratória dos dados}

A fim de determinar se ha diferenças em cada variável do solo, entre as duas profundidades de amostragem, aplicou-se o teste $\mathrm{t}$, cujos resultados mostram-se na tabela 1.

Os resultados demonstram que há diferenças nas variáveis: condutividade elétrica $(\mathrm{CE})$, matéria orgânica $(\mathrm{MO})$, argila $(\mathrm{A})$, fósforo $(\mathrm{P})$, magnésio $(\mathrm{Mg})$, boro $(\mathrm{B})$, cobre $(\mathrm{Cu})$, ferro $(\mathrm{Fe})$, manganês $(\mathrm{Mn})$ e zinco $(\mathrm{Zn})$. Por conseguinte o processo de avaliação de fertilidade de solo foi feito separadamente nas profundidades de amostragem: $0-20$ e $21-40 \mathrm{~cm}$.

Entretanto os resultados demonstram que as variáveis $\mathrm{pH}$, areia (a), silte (L), potássio $(\mathrm{K})$, cálcio $(\mathrm{Ca})$ e enxofre $(\mathrm{S})$, não apresentam diferenças entre as profundidades de amostragem. Por isso juntaram-se numa só profundeza de amostragem de 0 - $40 \mathrm{~cm}$ para os efeitos de avaliação da fertilidade do solo.

$\mathrm{O}$ valor de $\mathrm{t}$, permite também avaliar que as variáveis do solo diminuem com a profundidade de amostragem, exceto $\mathrm{pH}$, areia e silte que aumentaram, mais sem ter a magnitude necessária para apresentar diferenças estatisticamente significativas. 
Com os resultados da tabela 1 , e posterior reagrupamento das variáveis do solo na profundidade de 0 - 40, procedeurse logo à aplicação do teste de normalidade de Shapiro \& Wilk (1965).

Tabela 1. Teste de $\mathrm{t}$ para as variáveis do solo, entre as duas profundidades de amostragem: $0-20$ e $21-40 \mathrm{~cm}$.

\begin{tabular}{lcc}
\hline Variável & Valor t & $\operatorname{Pr}>\mathrm{t} \mid$ \\
\hline pH & 1,34 & $0,1825 \mathrm{n} . \mathrm{s}$. \\
Condutividade elétrica (CE) & $-2,22$ & $0,0272 *$ \\
Matéria orgânica (MO) & $-8,53$ & $0,0001 * *$ \\
Areia (a) & 0,44 & $0,65 \mathrm{n} . \mathrm{s}$. \\
Silte (L) & 0,44 & $0,66 \mathrm{n} . \mathrm{s}$. \\
Argila (A) & $-1,90$ & $0,049 *$ \\
Fósforo (P) & $-3,10$ & $0,002 * *$ \\
Potássio (K) & $-1,48$ & $0,14 \mathrm{n} . \mathrm{s}$. \\
Cálcio (Ca) & $-0,51$ & $0,61 \mathrm{n} . \mathrm{s}$. \\
Magnésio (Mg) & $-3,76$ & $0,0002 * *$ \\
Enxofre (S) & $-0,12$ & $0,90 \mathrm{n} . \mathrm{s.}$ \\
Boro (B) & $-2,17$ & $0,033 *$ \\
Cobre (Cu) & $-4,65$ & $0,0001 * *$ \\
Ferro (Fe) & $-2,31$ & $0,0217 *$ \\
Manganês (Mn) & $-2,47$ & $0,01 * *$ \\
Zinco (Zn) & $-2,98$ & $0,003 * *$ \\
\hline
\end{tabular}

Nas tabelas 2 e 3, são observados os resultados do teste de normalidade, incluindo as variáveis onde foi necessário a transformação.

Nas variáveis transformadas, é visto o valor de ñ, selecionado entre -2 e 2 ao qual foi elevado cada observação, e que permitiu obter a normalidade da distribuição de seus dados. 


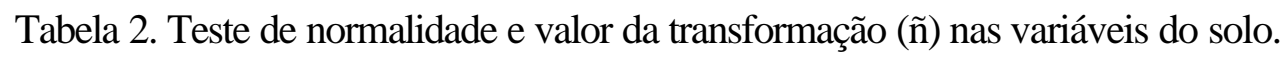

\begin{tabular}{|c|c|c|c|}
\hline Variável & $\bar{x}$ & $\tilde{\mathrm{n}}$ & Pr $<W$ \\
\hline $\mathrm{pH}_{0-40}$ & 6,64 & --- & $<0,0001^{* *}$ \\
\hline $\mathrm{CE}_{0-20}$ & 1,118 & $-0,1$ & 0,6651 \\
\hline $\mathrm{CE}_{21-40}$ & 1,304 & $-0,2$ & 0,0501 \\
\hline $\mathrm{MO}_{0-20}$ & 1,376 & 0,7 & 0,1693 \\
\hline $\mathrm{MO}_{21-40}$ & 1,041 & --- & $<0,0001 * *$ \\
\hline $\mathrm{a}_{0-40}$ & 20,94 & --- & $<0,0001 * *$ \\
\hline $\mathrm{L}_{0-40}$ & 59,16 & --- & $<0,0001 * *$ \\
\hline $\mathrm{A}_{0-20}$ & 11,201 & 0,8 & 0,1277 \\
\hline $\mathrm{A}_{21-40}$ & 4,327 & 0,5 & 0,0555 \\
\hline$P_{0-20}$ & 1.328 & 0,1 & 0,1306 \\
\hline$P_{21-40}$ & 1,276 & 0,1 & 0,3323 \\
\hline $\mathrm{K}_{0-40}$ & 0,928 & $-0,9$ & 0,7996 \\
\hline $\mathrm{Ca}_{0-40}$ & 2037,5 & --- & $0,0430 *$ \\
\hline $\mathrm{Mg}_{0-20}$ & 0,572 & $-0,2$ & 0,5037 \\
\hline $\operatorname{Mg}_{21-40}$ & 0,4606 & $-0,3$ & 0,9606 \\
\hline $\mathrm{S}_{0-40}$ & 234,85 & --- & $<0,0001 * *$ \\
\hline $\mathrm{B}_{0-20}$ & 0,19 & --- & $0,0107 *$ \\
\hline $\mathrm{B}_{21-40}$ & 0,15 & --- & $0,0363 *$ \\
\hline $\mathrm{Cu}_{0-20}$ & 1,377 & 0,6 & 0,6278 \\
\hline $\mathrm{Cu}_{21-40}$ & 0,9741 & $-0,1$ & 0,1424 \\
\hline $\mathrm{Fe}_{0-20}$ & 57,048 & --- & $<0,0001 * *$ \\
\hline $\mathrm{Fe}_{21-40}$ & 39,96 & --- & $<0,0001 * *$ \\
\hline $\mathrm{Mn}_{0-20}$ & 0,8046 & $-0,1$ & 0,5624 \\
\hline $\mathrm{Mn}_{21-40}$ & 0,479 & $-0,4$ & 0,5113 \\
\hline $\mathrm{Zn}_{0-20}$ & 0,9283 & $-0,2$ & 0,2153 \\
\hline $\mathrm{Zn}_{21}-40$ & 1,0285 & $-0,3$ & 0,0665 \\
\hline
\end{tabular}

(***) Com o nível de significância de 0,05 e 0,01, não apresentam distribuição normal. 
Tabela 3. Teste de normalidade e valor da transformação ( n) nas variáveis da folha.

\begin{tabular}{lccc}
\hline Variável & $\mathrm{x}^{(\mathrm{I})}$ & $\tilde{\mathrm{n}}$ & $\mathrm{Pr}<\mathrm{W}$ \\
\hline $\mathrm{N}$ & 2,6109 & --- & 0,089 \\
$\mathrm{P}$ & 2,265 & $-0,5$ & 0,1910 \\
$\mathrm{~K}$ & 4,239 & --- & 0,5339 \\
$\mathrm{Ca}$ & 0,827 & 0,5 & 0,8488 \\
$\mathrm{Mg}$ & 1,451 & $-0,3$ & 0,6701 \\
$\mathrm{~S}$ & 0,8593 & 0,1 & 0,0642 \\
$\mathrm{~B}$ & 10,944 & --- & $0,0410 *$ \\
$\mathrm{Cu}$ & 3,6006 & 0,6 & 0,2354 \\
$\mathrm{Fe}$ & 0,3103 & $-0,3$ & 0,0815 \\
$\mathrm{Mo}$ & 1,381 & --- & $<0,0001^{* *}$ \\
$\mathrm{Mn}$ & 0,6549 & $-0,1$ & 0,2107 \\
$\mathrm{Zn}$ & 0,1354 & $-0,7$ & 0,0990 \\
$\mathrm{Na}$ & 590 & --- & $0,0006^{* *}$
\end{tabular}

(1) médias elevadas ao valor correspondente de ñ.

(**) Com o nível de significância de 0,01, não apresentam distribuição normal.

Foi necessário também aplicar a transformação aos valores do rendimento, sendo o valor de $\tilde{n}=-0,1$ para obter a normalidade com a probabilidade da estatística $\mathrm{W}$ de $\operatorname{Pr}<$ $\mathrm{W}=0,893$.

Na tabela 2, se observam variáveis do solo $\mathrm{pH}_{0-40}, \mathrm{MO}_{21-40}, \mathrm{a}_{0-40}, \mathrm{~L}_{0-40}, \mathrm{Ca}_{0}$ - 40, $\mathrm{S}_{0-40}, \mathrm{~B}_{0-20}, \mathrm{~B}_{21-40}, \mathrm{Fe}_{0-20}, \mathrm{Fe}_{21-40}$ e na tabela 3 as variáveis da folha B, Mo e $\mathrm{Na}$, que ainda, aplicadas as transformações de Box \& Cox (1964) de -2 até 2, não foi possível obter sua normalidade na distribuição dos dados

Esses resultados poderiam ser explicados por inconsistência nas metodologias de determinação, contaminação ou outras causas pelo fato de aparecer dados muitos discrepantes ou repetitivos que afetaram a moda. 


\subsection{Analise de regressão por componentes principais}

\subsubsection{Balanço nutricional}

Para aplicar esta proposta, foram padronizados as variáveis com distribuição normal, continuando logo com a construção das combinações lineares e finalmente, estabelecendo-se o modelo de regressão do rendimento com as combinações lineares via método de stepwise.

Ao aplicar o procedimento stepwise, utilizaram-se todos os componentes principais obtidos, a fim de avaliar sua participação no $100 \%$ da variabilidade.

A tabela 4 mostra os resultados dos parâmetros dos componentes principais e de cada variável.

Tabela 4. Coeficientes dos componentes principais (C. P.) e de cada variável do solo e da folha, nas combinações lineares associadas al rendimento.

\begin{tabular}{lrrrr}
\hline & C.P. 2 & C.P. 4 & C.P. 6 & C. P. 19 \\
Coeficiente & 0,25313 & 0,33611 & 0,14187 & 0,23272 \\
Variável & & & & \\
\hline $\mathrm{CE}_{0-20}$ & 0,104323 & 0,042621 & 0,194218 & $-0,117804$ \\
$\mathrm{CE}_{21-40}$ & 0,07196 & 0,150585 & 0,045628 & 0,09748 \\
$\mathrm{MO}_{0-20}$ & $-0,308735$ & 0,107164 & $-0,056275$ & 0,036847 \\
$\mathrm{P}_{0-20}$ & $-0,313132$ & 0,206537 & 0,108124 & $-0,042737$ \\
$\mathrm{P}_{21-40}$ & $-0,306924$ & 0,052139 & 0,220478 & 0,031344 \\
$\mathrm{~K}_{0-40}$ & 0,309318 & 0,023899 & $-0,204016$ & $-0,036264$ \\
$\mathrm{Mg}_{0-20}$ & 0,108006 & $-0,066755$ & 0,052435 & $-0,184331$ \\
$\mathrm{Mg}_{21-40}$ & 0,045493 & 0,074794 & $-0,052778$ & 0,024313 \\
$\mathrm{~A}_{0-20}$ & 0,157327 & 0,084017 & 0,14842 & $-0,007573$ \\
$\mathrm{~A}_{21-40}$ & 0,18761 & $-0,045173$ & 0,208826 & $-0,068859$
\end{tabular}


Tabela 4. Coeficientes dos componentes principais (C. P.) e de cada variável do solo e da folha, nas combinações lineares associadas al rendimento.

\begin{tabular}{lrrrr}
\hline & C. P. 2 & C. P. 4 & C. P. 6 & C. P. 19 \\
$\mathrm{Mn}_{0-20}$ & $-0,054476$ & $-0,046853$ & 0,184052 & $-0,223581$ \\
$\mathrm{Mn}_{1-40}$ & $-0,106874$ & $-0,049569$ & 0,008657 & $-0,002646$ \\
$\mathrm{Cu}_{0-20}$ & $-0,070781$ & 0,145035 & $-0,231422$ & $-0,060559$ \\
$\mathrm{Cu} 1-40$ & 0,12144 & $-0,018704$ & $-0,102876$ & $-0,091326$ \\
$\mathrm{Zn}_{0-20}$ & 0,344701 & 0,055242 & $-0,129377$ & 0,112915 \\
$\mathrm{Zn}_{21-40}$ & 0,230048 & 0,104701 & $-0,375083$ & $-0,093853$ \\
$\mathrm{~N}$ (folha) & $-0,033641$ & $-0,012274$ & $-0,431781$ & 0,095717 \\
$\mathrm{P}$ (folha) & $-0,116309$ & 0,159376 & 0,215425 & $-0,36889$ \\
$\mathrm{~K}$ (folha) & 0,281155 & $-0,023356$ & 0,276468 & $-0,284065$ \\
$\mathrm{Ca}$ (folha) & $-0,16158$ & 0,474798 & $-0,106528$ & 0,369547 \\
$\mathrm{Mg}$ (folha) & 0,010846 & $-0,388173$ & 0,192436 & 0,446829 \\
$\mathrm{~S}$ (folha) & 0,257831 & 0,348997 & 0,37929 & 0,364232 \\
$\mathrm{Cu}$ (folha) & 0,283248 & $-0,190338$ & 0,009167 & 0,171474 \\
$\mathrm{Fe}$ (folha) & 0,106413 & 0,364118 & 0,06986 & $-0,050287$ \\
$\mathrm{Mn}$ (folha) & $-0,030545$ & $-0,148471$ & 0,145219 & 0,348279 \\
$\mathrm{Zn}$ (folha) & $-0,205475$ & $-0,379492$ & $-0,029124$ & $-0,012576$ \\
\hline
\end{tabular}

O modelo obtido apresentou uma propriedade de ajuste do 51,98 \% $\left(\mathrm{r}^{2}\right)$, significativo ao nível de $1 \%$ de probabilidade, estando a normalidade dos resíduos padronizados, em virtude de se ter todas as variáveis com sua distribuição normal.

\subsubsection{Determinação dos valores a ser propostos como de referência, no balanço nutricional ótimo}


Com os estimadores da tabela 4, construiu-se no formato de calculo do aplicativo Excel 2000 (Microsoft $®$, 2000), uma folha de calculo a fim de estimar os $\mathrm{kg}$ cacho $^{-1}$ em cada uma das amostras e logo, foram separados em cachos acima e abaixo dos $18 \mathrm{~kg}$.

Tive-se a precaução de fazer a transformação prévia das variáveis (de acordo as tabelas 2 e 3), antes de proceder-se às operações de multiplicar por cada uns dos estimadores da tabela 4.

Obtido o valor transformado do rendimento, aplicou-se o inverso de $\tilde{\mathrm{n}}=(-) 0,1 \mathrm{ou}$ (-) $\log 0,1$ para aparecer em unidades de campo de $\mathrm{kg} \mathrm{cacho}^{-1}$.

Nas tabelas 5 e 6 observam-se os resultados.

Tabela 5. Médias aritméticas nas varáveis do solo, nas plantas acima e abaixo dos $18 \mathrm{~kg}$ cacho $^{-1}$, classificadas pelos pesos estimados por componentes principais.

\begin{tabular}{lcc}
\hline Variáveis & $10,96-17,9 \mathrm{~kg} \mathrm{cacho}^{-1}$ & $>18 \mathrm{~kg} \mathrm{cacho}^{-1}$ \\
\hline $\mathrm{pH}_{0-40}$ & 6,66 & 6,59 \\
$\mathrm{CE}_{0-20}\left(\mathrm{dS} \mathrm{m}^{-1}\right)$ & 0,309 & 0,408 \\
$\mathrm{CE}_{21-40}\left(\mathrm{dS} \mathrm{m}^{-1}\right)$ & 0,255 & 0,336 \\
$\mathrm{MO}_{0-20}\left(\mathrm{~g} \mathrm{~kg}^{-1}\right)$ & 15,5 & 16,96 \\
$\mathrm{MO}_{21-40}\left(\mathrm{~g} \mathrm{~kg}^{-1}\right)$ & 10,1 & 12,01 \\
$\mathrm{P}_{0-20}\left(\mathrm{mg} \mathrm{dm}^{-3}\right)$ & 16,78 & 18,35 \\
$\mathrm{P}_{21-40}\left(\mathrm{mg} \mathrm{dm}^{-3}\right)$ & 10,75 & 14,27 \\
$\mathrm{~K}_{0-40}\left(\mathrm{mmolc} \mathrm{dm}^{-3}\right)$ & 1,058 & 1,21 \\
$\mathrm{Ca}_{0-40}\left(\mathrm{mmol}_{\mathrm{c}} \mathrm{dm}^{-3}\right)$ & 87,89 & 111,44 \\
$\mathrm{Mg}_{0-20}\left(\mathrm{mmol}_{\mathrm{c}} \mathrm{dm}^{-3}\right)$ & 16,54 & 15,52 \\
$\mathrm{Mg}_{21-40}\left(\mathrm{mmol}_{\mathrm{c}} \mathrm{dm}^{-3}\right)$ & 13,22 & 13,30 \\
$\mathrm{~S}_{0-40}\left(\mathrm{mg} \mathrm{dm}^{-3}\right)$ & 212,83 & 249,91 \\
$\mathrm{a}_{0-40}(\%)$ & 19,12 & 27,92 \\
$\mathrm{~L}_{0-40}(\%)$ & 60,26 & 54,92
\end{tabular}


Tabela 5. Médias aritméticas nas varáveis do solo, nas plantas acima e abaixo dos $18 \mathrm{~kg}$ cacho $^{-1}$, classificadas pelos pesos estimados por componentes principais.

\begin{tabular}{lcc}
\hline Variáveis & $10,96-17,9 \mathrm{~kg} \mathrm{cacho}^{-1}$ & $>18 \mathrm{~kg} \mathrm{cacho}^{-1}$ \\
\hline $\mathrm{A}_{0-20}(\%)$ & 21,42 & 16,98 \\
$\mathrm{~A}_{21-40}(\%)$ & 19,39 & 16,29 \\
$\mathrm{~B}_{0-20}\left(\mathrm{mg} \mathrm{dm}^{-3}\right)$ & 0,187 & 0,207 \\
$\mathrm{~B}_{21-40}\left(\mathrm{mg} \mathrm{dm}^{-3}\right)$ & 0,151 & 0,155 \\
$\mathrm{Cu}_{0-20}\left(\mathrm{mg} \mathrm{dm}^{-3}\right)$ & 1,72 & 1,64 \\
$\mathrm{Cu}_{21-40}\left(\mathrm{mg} \mathrm{dm}^{-3}\right)$ & 1,29 & 1,32 \\
$\mathrm{Fe}_{0-20}\left(\mathrm{mg} \mathrm{dm}^{-3}\right)$ & 54,78 & 65,75 \\
$\mathrm{Fe}_{21-40}\left(\mathrm{mg} \mathrm{dm}^{-3}\right)$ & 38,78 & 44,48 \\
$\mathrm{Mn}_{0-20}\left(\mathrm{mg} \mathrm{dm}^{-3}\right)$ & 8,97 & 8,11 \\
$\mathrm{Mn}_{21-40}\left(\mathrm{mg} \mathrm{dm}^{-3}\right)$ & 6,48 & 5,57 \\
$\mathrm{Zn}_{0-20}\left(\mathrm{mg} \mathrm{dm}^{-3}\right)$ & 1,33 & 2,05 \\
$\mathrm{Zn}_{21-40}\left(\mathrm{mg} \mathrm{dm}^{-3}\right)$ & 0,86 & 1,16 \\
\hline
\end{tabular}

Ainda, se observa que na tabela 5 aparecem as variáveis $\mathrm{pH}{ }_{0-40}, \mathrm{MO}_{21-40}, \mathrm{a}_{0-40}$, $\mathrm{L}_{0-40}, \mathrm{Ca}_{0-40}, \mathrm{~S}_{0-40}, \mathrm{~B}_{0-20}, \mathrm{~B}_{21-40}, \mathrm{Fe}_{0-20}, \mathrm{Fe}_{21-40}$ e na tabela 6 as variáveis da folha $\mathrm{B}$, Mo e $\mathrm{Na}$, que muito a pesar de que não formaram parte dos componentes principais (tabela 4), por não ter distribuição normal em seus dados (tabelas 2 e 3), seguem sendo utilizadas. Estou aconteceu, porque na folha de calculo não foram apagadas intencionalmente durante o processo de agrupamento pelo rendimento estimado, e o software as ordenou, munidas todas.

Como se lembrou, essas variáveis estatisticamente não são confiáveis, nem podem ser utilizadas para estimar o rendimento, não obstante, no processo de agrupamento de suas homologas, poderiam dar indicio de sua participação no balanço geral da planta e do solo. 
Desta maneira poderiam contribuir na avaliação do balanço nutricional, por enquanto es resolvido seus problemas relacionados com a falta da normalidade da distribuição de seus dados.

Tabela 6. Médias aritméticas nas varáveis da folha, nas plantas acima e abaixo dos $18 \mathrm{~kg}$ cacho $^{-1}$, classificadas pelo pesos estimados por componentes principais.

\begin{tabular}{lcc}
\hline \multirow{2}{*}{ Variáveis } & \multicolumn{2}{c}{ Classes em kg cacho $^{-1}$} \\
\hline $\mathrm{N}$ & $10,96-17,9 \mathrm{~kg} \mathrm{cacho}^{-1}$ & $>18 \mathrm{~kg} \mathrm{cacho}^{-1}$ \\
$\mathrm{P}$ & 25,6 & 27,9 \\
$\mathrm{~K}$ & 1,91 & 2,09 \\
$\mathrm{Ca}$ & 42,89 & 40,45 \\
$\mathrm{Mg}$ & 7,16 & 5,67 \\
$\mathrm{~S}$ & 2,94 & 2,68 \\
& 2,4 & 1,50 \\
$\mathrm{~B}$ & & $\left(\mathrm{gg} \mathrm{kg}^{-1}\right)$ \\
$\mathrm{Cu}$ & 9,08 & 12,21 \\
$\mathrm{Fe}$ & 8,49 & 8,33 \\
$\mathrm{Mn}$ & 46,65 & 62,47 \\
$\mathrm{Zn}$ & 68,64 & 69,46 \\
$\mathrm{Mo}$ & 19,27 & 12,40 \\
$\mathrm{Na}$ & 1,313 & 1,428 \\
\hline
\end{tabular}

\subsection{Análise de regressão múltipla}

\subsubsection{Balanço nutricional}


Partindo dos resultados das tabelas 1,2 e 3, procedeu-se ao calculo, pelo método do stepwise, do modelo polinômico de regressão múltipla que melhor se adapte ás variáveis estudadas de solo e folhas.

Para esta procedimento, participaram do calculo todas as variáveis, estejam ou não normalmente distribuídas e as variáveis em que foi necessária a transformação para obter distribuição normal, foram analisadas na condição transformada.

A tabela 7 reúne os coeficientes das variáveis que compõem o modelo determinado. O modelo ajusta-se com uma aproximação de 99,99\% ( $\left.\mathrm{R}^{2}\right)$, com normalidade dos resíduos padronizados $(\operatorname{Pr}<\mathrm{w}=0,2554)$.

Tabela 7. Coeficientes das variáveis que compõem o modelo de regressão múltipla, entre as variáveis do solo e da folha.

\begin{tabular}{lccc}
\hline Variáveis & $\tilde{\mathrm{n}}$ & Coeficiente & $\mathrm{F}$ \\
\hline $\mathrm{CE}_{0-20}$ & $-0,1$ & 0,055 & $* *$ \\
$\mathrm{P}_{21-40}$ & $-0,1$ & 0,0309 & $*$ \\
$\mathrm{a}_{0-40}$ & --- & 0,0045 & $* *$ \\
$\mathrm{~L}_{0-40}$ & --- & 0,00046 & $* *$ \\
$\mathrm{~A}_{0-20}$ & 0,8 & 0,0056 & $* *$ \\
$\mathrm{~A}_{21-40}$ & 0,5 & 0,02 & $* *$ \\
$\mathrm{~S}$ (folha) & 0,1 & 0,217 & $* *$ \\
$\mathrm{P}$ (folha) & $-0,5$ & $-0,018$ & $*$ \\
$\mathrm{Ca}$ (folha) & 0,5 & 0,026 & $* *$ \\
$\mathrm{Zn}$ (folha) & $-0,7$ & $-0,1626$ & $* *$ \\
\hline
\end{tabular}

4.4.2 Determinação dos valores a ser propostos como de referência, no balanço nutricional ótimo 
Com os estimadores do modelo de regressão múltipla da tabela 7 , construiu-se no formato de calculo do aplicativo Excel 2000 (Microsoft ®, 2000), outra folha de calculo a fim de estimar os $\mathrm{kg} \mathrm{cacho}^{-1}$ em cada uma das amostras.

Tive-se a precaução de fazer a transformação previa das variáveis (de acordo as tabelas 2 e 3), antes de fazer as operações de multiplicar por cada uns dos estimadores da tabela 7.

Obtido o valor transformado da massa do cacho aplicou-se o inverso de $\tilde{\mathrm{n}}=(-)$ 0,1 ou (-) $\log 0,1$ para aparecer em unidades de campo de $\mathrm{kg}$ cacho $^{-1}$.

Assim estimado a massa do cacho, procedeu-se à separação da população em dois agrupamentos: acima e abaixo de $18 \mathrm{~kg} \mathrm{cacho}^{-1}$.

Nas tabelas 8 e 9 observam-se os resultados. Assim, na coluna de $>18 \mathrm{~kg}$ cacho $^{-1}$ aparecem as médias das variáveis da tabela 7, consideradas valores de referência para os efeitos de diagnóstico nutricional e avaliação da fertilidade do solo.

Tabela 8. Médias aritméticas nas variáveis do solo, nas plantas acima e abaixo dos $18 \mathrm{~kg}$ cacho $^{-1}$, classificadas pelo pesos estimados por regressão múltipla.

\begin{tabular}{lcc}
\hline Variáveis & $12,19-17,81 \mathrm{~kg} \mathrm{cacho}^{-1}$ & $>18 \mathrm{~kg} \mathrm{cacho}^{-1}$ \\
\hline $\mathrm{pH}_{0-40}$ & 6,56 & 6,71 \\
$\mathrm{CE}_{0-20}\left(\mathrm{dS} \mathrm{m}^{-1}\right)$ & $(*), 297$ & 0,356 \\
$\mathrm{CE}_{21-40}\left(\mathrm{dS} \mathrm{m}^{-1}\right)$ & 0,251 & 0,286 \\
$\mathrm{MO}_{0-20}\left(\mathrm{~g} \mathrm{~kg}^{-1}\right)$ & 14,2 & 17,1 \\
$\mathrm{MO}_{21-40}\left(\mathrm{~g} \mathrm{~kg}^{-1}\right)$ & 8,8 & 11,8 \\
$\mathrm{P}_{0-20}\left(\mathrm{mg} \mathrm{dm}^{-3}\right)$ & 16,92 & 19,40 \\
$\mathrm{P}_{21-40}\left(\mathrm{mg} \mathrm{dm}^{-3}\right)(*)$ & 9,46 & 13,28 \\
$\mathrm{~K}_{0-40}\left(\mathrm{mmol}_{\mathrm{c}} \mathrm{dm}^{-3}\right)$ & 0,98 & 1,18 \\
$\mathrm{Ca}_{0-40}\left(\mathrm{mmol}_{\mathrm{c}} \mathrm{dm}^{-3}\right)$ & 97,41 & 168,75 \\
$\mathrm{Mg}_{0-20}\left(\mathrm{mmol}_{\mathrm{c}} \mathrm{dm}^{-3}\right)$ & 15,67 & 16,41 \\
$\mathrm{Mg}_{21-40}\left(\mathrm{mmolc}_{\mathrm{dm}}^{-3}\right)$ & 12,45 & 13,98
\end{tabular}


Tabela 8. Médias aritméticas nas variáveis do solo, nas plantas acima e abaixo dos $18 \mathrm{~kg}$ cacho $^{-1}$, classificadas pelos pesos estimados por regressão múltipla.

\begin{tabular}{|c|c|c|}
\hline Variáveis & $12,19-17,81 \mathrm{~kg}$ cacho $^{-1}$ & $>18 \mathrm{~kg} \mathrm{cacho}^{-1}$ \\
\hline $\mathrm{S}_{0-40}\left(\mathrm{mg} \mathrm{dm}^{-3}\right)$ & 194,4 & 842,1 \\
\hline $\mathrm{a}_{0-40}(\%) \quad(*)$ & 17,59 & 23,86 \\
\hline $\mathrm{L}_{0-40}(\%)$ & 61,34 & 57,26 \\
\hline $\mathrm{A}_{0-20}(\%) \quad(*)$ & 21,82 & 19,35 \\
\hline $\mathrm{A}_{21-40}(\%)$ & 20,77 & 17,43 \\
\hline $\mathrm{B}_{0-20}\left(\mathrm{mg} \mathrm{dm}^{-3}\right)$ & 0,204 & 0,12 \\
\hline $\mathrm{B}_{21-40}\left(\mathrm{mg} \mathrm{dm}^{-3}\right)$ & 0,158 & 0,09 \\
\hline $\mathrm{Cu}_{0-20}\left(\mathrm{mg} \mathrm{dm}^{-3}\right)$ & 1,67 & 1,73 \\
\hline $\mathrm{Cu}_{21-40}\left(\mathrm{mg} \mathrm{dm}^{-3}\right)$ & 1,27 & 1,32 \\
\hline $\mathrm{Fe}_{0-20}\left(\mathrm{mg} \mathrm{dm}^{-3}\right)$ & 60,46 & 51,08 \\
\hline $\mathrm{Fe}_{21-40}\left(\mathrm{mg} \mathrm{dm}^{-3}\right)$ & 49,98 & 37,33 \\
\hline $\mathrm{Mn}_{0-20}\left(\mathrm{mg} \mathrm{dm}^{-3}\right)$ & 9,44 & 8,24 \\
\hline $\mathrm{Mn}_{21-40}\left(\mathrm{mg} \mathrm{dm}^{-3}\right)$ & 7,02 & 5,71 \\
\hline $\mathrm{Zn}_{0-20}\left(\mathrm{mg} \mathrm{dm}^{-3}\right)$ & 1,23 & 1,68 \\
\hline $\mathrm{Zn}_{21-40}\left(\mathrm{mg} \mathrm{dm}^{-3}\right)$ & 0,78 & 1,056 \\
\hline
\end{tabular}

(*) Variáveis que compõem o modelo de regressão múltipla

A consideração é válida porque este procedimento parte do principio que, se podem obter ou estimar o rendimento ou outra variável de interesse, partindo do conhecimento de outras variáveis (geralmente nutrientes) e a relação entre essas variáveis esta dada por uma função matemática cujos coeficientes são vistos na tabela 7.

Entretanto, como no ponto 4.3.2, também aparecem as outras variáveis analisadas que não compõem o modelo de regressão múltipla da tabela 7, não obstante seu calculo poderia orientar na avaliação do balanço geral do solo e na folha, estando ciente que não possuem uma relação funcional com o rendimento 
Provavelmente haveria um erro maior que no caso da analises dos componentes principais, pelo fato de que só 10 , das 39 variáveis amostradas estimam o rendimento. Utilizando menos variáveis, fica prejudicada a previsão da massa do cacho.

Tabela 9. Médias aritméticas nas varáveis da folha, nas plantas acima e abaixo dos $18 \mathrm{~kg}$ cacho $^{-1}$, classificadas pelos pesos estimados por regressão múltipla.

\begin{tabular}{|c|c|c|}
\hline Variáveis & $12,19-17,81 \mathrm{~kg} \mathrm{cacho}^{-1}$ & $>18 \mathrm{~kg} \mathrm{cacho}^{-1}$ \\
\hline & \multicolumn{2}{|c|}{$\left(\mathrm{g} \mathrm{kg}^{-1}\right)$} \\
\hline $\mathrm{N}$ & 25,6 & 26,4 \\
\hline $\mathrm{P} \quad(*)$ & 1,97 & 1,92 \\
\hline $\mathrm{K}$ & 44,3 & 40,7 \\
\hline $\mathrm{Ca}(*)$ & 7,34 & 6,42 \\
\hline $\mathrm{Mg}$ & 3,01 & 2,78 \\
\hline \multirow[t]{2}{*}{$\mathrm{S} \quad(*)$} & 2,7 & 1,79 \\
\hline & \multicolumn{2}{|c|}{$\left(\mathrm{mg} \mathrm{kg}^{-1}\right)$} \\
\hline B & 10,64 & 15,5 \\
\hline $\mathrm{Cu}$ & 8,81 & 8,14 \\
\hline $\mathrm{Fe}$ & 43,38 & 55,65 \\
\hline $\mathrm{Mn}$ & 76,11 & 63,1 \\
\hline $\mathrm{Zn} \quad(*)$ & 23,07 & 14,13 \\
\hline Mo & 1,4 & 1,105 \\
\hline $\mathrm{Na}$ & 568 & 581 \\
\hline
\end{tabular}

(*) Variáveis que compõem o modelo de regressão múltipla

\subsection{Média aritmética das plantas excepcionais}

\subsubsection{Balanço nutricional}


Como nos procedimentos anteriores, procedeu-se ao calculo das médias, em função dos resultados das tabelas 1, 2 e 3 e participaram todas as variáveis ainda que estivessem ou não, normalmente distribuídas.

As variáveis, de acordo aos valores de $\tilde{n}$ das ta belas 2 e 3 foram transformadas antes de fazer a operações de separar ou agrupar o acima e abaixo de $18 \mathrm{~kg}$ cacho $^{-1}$.

Este procedimento é mais simples e direto e, em função dos pesos observados em campo, foram feitos os agrupamentos. As tabelas 10 e 11 mostram os resultados.

Tabela 10. Médias aritméticas nas varáveis do solo, nas plantas acima e abaixo dos18 kg cacho $^{-1}$, classificadas diretamente pelos pesos observados.

\begin{tabular}{lcc}
\hline Variáveis & $8,6-17,99 \mathrm{~kg} \mathrm{cacho}^{-1}$ & $>18 \mathrm{~kg} \mathrm{cacho}^{-1}$ \\
\hline $\mathrm{pH}_{0-40}$ & 6,63 & 6,66 \\
$\mathrm{CE}_{0-20}\left(\mathrm{dS} \mathrm{m}^{-1}\right)$ & 0,379 & 0,421 \\
$\mathrm{CE}_{21-40}\left(\mathrm{dS} \mathrm{m}^{-1}\right)$ & 0,307 & 0,368 \\
$\mathrm{MO}_{0-20}\left(\mathrm{~g} \mathrm{~kg}^{-1}\right)$ & 15,73 & 17,47 \\
$\mathrm{MO}_{21-40}\left(\mathrm{~g} \mathrm{~kg}^{-1}\right)$ & 9,4 & 11,71 \\
$\mathrm{a}_{0-40}(\%)$ & 20,59 & 21,10 \\
$\mathrm{~L}_{0-40}(\%)$ & 59,28 & 58,84 \\
$\mathrm{~A}_{0-20}(\%)$ & 21,11 & 19,51 \\
$\mathrm{~A}_{21-40}(\%)$ & 19,23 & 19,23 \\
$\mathrm{P}_{0-20}\left(\mathrm{mg} \mathrm{dm}^{-3}\right)$ & 23,39 & 25,74 \\
$\mathrm{P}_{21-40}\left(\mathrm{mg} \mathrm{dm}^{-3}\right)$ & 14,11 & 16,61 \\
$\mathrm{~K}_{0-40}\left(\mathrm{mmol}_{\mathrm{c}} \mathrm{dm}^{-3}\right)$ & 1,408 & 1,408 \\
$\mathrm{Ca}_{0-40}\left(\mathrm{mmol}_{\mathrm{c}} \mathrm{dm}^{-3}\right)$ & 90,29 & 118,79 \\
$\mathrm{Mg}_{0-20}\left(\mathrm{mmol}_{\mathrm{c}} \mathrm{dm}^{-3}\right)$ & 18,87 & 18,37 \\
$\mathrm{Mg}_{21-40}\left(\mathrm{mmol}_{\mathrm{c}} \mathrm{dm}^{-3}\right)$ & 14,57 & 15,61 \\
$\mathrm{~S}_{0-40}\left(\mathrm{mg} \mathrm{dm}^{-3}\right)$ & 171,04 & 328,13 \\
$\mathrm{~B}_{0-20}\left(\mathrm{mg} \mathrm{dm}^{-3}\right)$ & 0,203 & 0,195
\end{tabular}


Tabela 10. Médias aritméticas nas varáveis do solo, nas plantas acima e abaixo dos 18 $\mathrm{kg} \mathrm{cacho}^{-1}$, classificadas diretamente pelos pesos observados.

\begin{tabular}{lcc}
\hline Variáveis & $8,6-17,99 \mathrm{~kg} \mathrm{cacho}^{-1}$ & $>18 \mathrm{~kg} \mathrm{cacho}^{-1}$ \\
\hline $\mathrm{B}_{21-40}\left(\mathrm{mg} \mathrm{dm}^{-3}\right)$ & 0,145 & 0,166 \\
$\mathrm{Cu}_{0-20}\left(\mathrm{mg} \mathrm{dm}^{-3}\right)$ & 1,74 & 1,78 \\
$\mathrm{Cu}_{21-40}\left(\mathrm{mg} \mathrm{dm}^{-3}\right)$ & 1,35 & 1,51 \\
$\mathrm{Fe}_{0-20}\left(\mathrm{mg} \mathrm{dm}^{-3}\right)$ & 51,65 & 71,85 \\
$\mathrm{Fe}_{21-40}\left(\mathrm{mg} \mathrm{dm}^{-3}\right)$ & 36,96 & 48,19 \\
$\mathrm{Mn}_{0-20}\left(\mathrm{mg} \mathrm{dm}^{-3}\right)$ & 10,72 & 13,18 \\
$\mathrm{Mn}_{21-40}\left(\mathrm{mg} \mathrm{dm}^{-3}\right)$ & 8,88 & 8,51 \\
$\mathrm{Zn}_{0-20}\left(\mathrm{mg} \mathrm{dm}^{-3}\right)$ & 1,63 & 2,25 \\
$\mathrm{Zn}_{21-40}\left(\mathrm{mg} \mathrm{dm}^{-3}\right)$ & 1,11 & 1,69 \\
\hline
\end{tabular}

Tabela 11. Médias aritméticas nas variáveis da folha, nas plantas acima e abaixo dos 18 $\mathrm{kg}$ cacho $^{-1}$, classificadas diretamente pelos pesos observados.

\begin{tabular}{lcc}
\hline Variáveis & $8,60-17,99 \mathrm{~kg} \mathrm{cacho}^{-1}$ & $>18 \mathrm{~kg} \mathrm{cacho}^{-1}$ \\
\hline $\mathrm{N}$ & 25,6 & $\left(\mathrm{~g} \mathrm{~kg}^{-1}\right)$ \\
$\mathrm{P}$ & 1,97 & 27,3 \\
$\mathrm{~K}$ & 43,0 & 2,01 \\
$\mathrm{Ca}$ & 7,18 & 40,6 \\
$\mathrm{Mg}$ & 2,99 & 6,58 \\
$\mathrm{~S}$ & 2,45 & 2,82 \\
& & 1,84 \\
$\mathrm{~B}$ & & \\
$\mathrm{Cu}$ & 10,13 & 12,12 \\
$\mathrm{Fe}$ & 8,58 & 8,36 \\
& 50,75 & 63,64
\end{tabular}


Tabela 11. Médias aritméticas nas variáveis da folha, nas plantas acima e abaixo dos 18 $\mathrm{kg} \mathrm{cacho}^{-1}$, classificadas diretamente pelos pesos observados.

\begin{tabular}{lcc}
\hline Variáveis & $8,60-17,99 \mathrm{~kg} \mathrm{cacho}^{-1}$ & $>18 \mathrm{~kg} \mathrm{cacho}^{-1}$ \\
\hline \multirow{2}{*}{$\left.\mathrm{mn}_{\mathrm{mg} \mathrm{kg}}^{-1}\right)$} & \\
$\mathrm{Zn}$ & 74,68 & 74,54 \\
$\mathrm{Mo}$ & 21,92 & 18,26 \\
$\mathrm{Na}$ & 1,439 & 1,297 \\
\end{tabular}

\subsubsection{Determinação dos valores a ser propostos como de referência, no balanço nutricional ótimo}

Este procedimento parte do principio no qual, a média aritmética ao ser estimada em grupos de plantas excepcionais, já pela distribuição normal das observações, permite obter uma estimativa segura dos valores do elemento a ser considerado como referência.

De acordo ao principio, as variáveis: No solo o $\mathrm{pH}_{0-40}, \mathrm{MO}_{21-40}, \mathrm{a}_{0-40}, \mathrm{~L}_{0-40}, \mathrm{Ca}_{0-40}$, $\mathrm{S}_{0-40}, \mathrm{~B}_{0-20}, \mathrm{~B}_{21-40}, \mathrm{Fe}_{0-20}$ e $\mathrm{Fe}_{21-40}$ e na folha o $\mathrm{B}$, Mo e $\mathrm{Na}$, não são confiáveis por não ter distribuição normal, o seu calculo, entretanto, poderia orientar na avaliação do balanço geral do solo e na folha.

As tabelas 10 e 11 mostram na coluna de $>18 \mathrm{~kg}$ cacho $^{-1}$ as médias das variáveis a ser consideradas valores de referência para os efeitos de diagnóstico nutricional e avaliação da fertilidade do solo.

Desta maneira acredita-se que as médias aritméticas obtidas, representam o balanço nutricional desejável, podendo-se fazer diagnósticos posteriores confiáveis, com as diversas propostas, discutidas no itens 2.5.2.

4.6 Comparação dos valores de referência e o balanço ótimo obtido pelos três procedimentos. 
Confrontando os resultados das tabelas 5, 6, 8, 9, 10 e 11 dos três procedimentos de obtenção de valores de referência e do balanço nutricional ótimo nas plantas excepcionais ou com massa do cacho maior a $18 \mathrm{~kg}$, apreciam-se diferenças e coincidências entre as variáveis avaliadas.

Com a finalidade de selecionar criteriosamente quais dos três procedimentos acerta mais com a média da massa dos cachos com mais de $18 \mathrm{~kg}$, foi calculada a massa do cacho a partir das médias das variáveis no solo e na folha, das plantas com mais de 18 $\mathrm{kg}$ das tabelas 5, 6, 8, 9, 10 e 11 .

A tabela 12 mostra a média da massa do cacho das plantas excepcionais ou >18 $\mathrm{kg}$ cacho $^{-1}$ obtidas pelos modelos de regressão do rendimento com as combinações lineares (tabelas 5 e 6), a qual foi de 19,87 $\mathrm{kg} \mathrm{cacho}^{-1}$, de regressão múltipla (tabelas 8 e 9), a qual foi de $21,56 \mathrm{~kg} \mathrm{cacho}^{-1}$ e pelos pesos observados (tabelas $10 \mathrm{e} \mathrm{11),} \mathrm{a} \mathrm{qual} \mathrm{foi}$ de $20,18 \mathrm{~kg} \mathrm{cacho}^{-1}$.

Tabela 12. Média da massa dos cachos nas plantas excepcionais ou $>18 \mathrm{~kg}$ cacho $^{-1}$, obtidas pelos modelos de regressão com as combinações lineares, regressão múltipla, por a massa ou peso observado, e ademais novamente a massa do cacho calculada a partir dos nutrientes das mesmas plantas, pero pelos modelos de regressão múltipla (R. M.) e pelas combinações lineares (C. L.)

\begin{tabular}{lccc}
\hline & $\begin{array}{c}\text { Média da massa do cacho } \\
\text { nas plantas } \\
\text { Procedimento }\end{array}$ & $\begin{array}{c}\text { Massa do cacho } \\
\text { calculada } \\
\text { por R. M. }\end{array}$ & $\begin{array}{c}\text { Massa do cacho } \\
\text { calculada } \\
\text { por C. L. }\end{array}$ \\
\hline C.P. & 19,87 & 18,77 & 19,46 \\
R.M. & 21,56 & 21,39 & 13,44 \\
Peso observado & 20,18 & 19,33 & 15,22 \\
\hline
\end{tabular}

Nessa mesma tabela observa-se também as respectivas massas do cacho, pero calculadas novamente pelo modelo de regressão múltipla e das combinações lineares, a 
partir das médias dos nutrientes em solos e folhas das plantas excepcionais ou $>18 \mathrm{~kg}$ cacho $^{-1}$ das tabelas 5, 6, 8, 9, 10 e 11 .

$\mathrm{Na}$ primeira linha (C. L.) da tabela 12, observa-se massas do cacho muito semelhantes. Entretanto, na segunda e terceira linha (R. M. e peso observado) gritantes diferenças são obtidas no cálculo da massa do cacho.

Este fato pode ser explicado através das propriedades da analise dos componentes principais, sendo uma delas a linearidade da relação funcional, que também pode ser determinada em algumas variáveis por regressão múltipla e não é possível por separação direta através dos peso observados. A outra propriedade dos componentes principais é a existência e a explicação da variação total dos dados originais, condição que não pode ser explicada por regressão múltipla, e muito menos por separação direta através dos pesos observados nas populações de referência.

Estas propriedades proporcionam vantagens muito importantes porque por esta metodologia pode-se avaliar simultaneamente numerosas e diversas variáveis, alem disso dispensa a necessidade de valores de referência (fato muito importante em áreas e culturas novas) e de outras metodologias de interpretação de análise, ao poder associar ao rendimento esperado, uma combinação ou balanço de médias das variáveis estudadas.

Portanto, estes resultados indicam e põem em evidência os erros dos diagnósticos nutricionais cujos valores de referência estejam baseados nas médias aritméticas das variáveis das plantas excepcionais onde não exista una relação, tal é o caso por separação direta através dos pesos observados.

Outra vantagem deste procedimento é que permite classificar as variáveis estudadas mediante o calculo da contribuição total de cada variável (tabelas 13 e 14).

A tabela 13, mostra como entre as variáveis do solo, o nutriente zinco na profundidade de amostragem de 020 centímetros é o que mais contribui na estimação do rendimento e na tabela 14, mostra-se os nutrientes nas folhas, onde agora aparece o elemento enxofre, na maior contribuição na estimação do rendimento.

É importante mencionar que estes valores, não devem ser tomados como desbalanço nutricional porque referem-se á flutuação das variáveis no banco de dados, de modo que os que mais contribuem, com pequenas variações, observariam-se grandes 
variações no rendimento. Também é válido destacar que em algumas variáveis aparece o sinal negativo, isto não implica o efeito depressivo sobre a produção, pois os sinais ocorrem por ajustes matemáticos.

Tabela 13. Contribuição total de cada variável do solo, nos coeficientes das combinações lineares.

\begin{tabular}{llcllc}
\hline Variáveis & Contribuição & $\mathrm{X} 100$ & Variáveis & Contribuição & x100 \\
\hline $\mathrm{CE}_{0-20}$ & 0,040870986 & 4 & $\mathrm{AA}_{0-20}$ & 0,087357094 & 8,7 \\
$\mathrm{CE}_{21-40}$ & 0,097987149 & 9,7 & $\mathrm{AA}_{21-40}$ & 0,0459079 & 4,5 \\
$\mathrm{MO}_{0-20}$ & $(-) 0,041539899$ & $(-) 4$ & $\mathrm{Mn}_{0-20}$ & $(-) 0,055457585$ & $(-) 5,5$ \\
$\mathrm{P}_{0-20}$ & $(-) 0,004450155$ & $(-) 0,4$ & $\mathrm{Mn}_{21-40}$ & $(-) 0,043101261$ & $(-) 4,3$ \\
$\mathrm{P}_{21-40}$ & $(-) 0,021593643$ & $(-) 2$ & $\mathrm{Cu}_{0-20}$ & $(-) 0,01609421$ & $(-) 1,6$ \\
$\mathrm{~K}_{0-40}$ & 0,04894725 & 4,8 & $\mathrm{Cu}_{21-40}$ & $(-) 0,011394899$ & $(-) 1,1$ \\
$\mathrm{Mg}_{0-20}$ & $(-) 0,030556021$ & $(-) 3$ & $\mathrm{Zn}_{0-20}$ & 0,113744417 & 11,3 \\
$\mathrm{Mg}_{21-40}$ & 0,034825161 & 3 & $\mathrm{Zn}_{21-40}$ & 0,018368608 & 1,8 \\
\hline
\end{tabular}

Tabela 14. Contribuição total de cada variável da folha, nos coeficientes das combinações lineares.

\begin{tabular}{llcllc}
\hline Variáveis & Contribuição & x100 & Variáveis & Contribuição & x100 \\
\hline $\mathrm{S}$ & 0,321140086 & 32,1 & $\mathrm{Mg}$ & 0,003563561 & 0,3 \\
$\mathrm{~N}$ & $(-) 0,051622471$ & $(-) 5,1$ & $\mathrm{Cu}$ & 0,048930013 & 4,8 \\
$\mathrm{P}$ & $(-) 0,031159166$ & $(-)) 3,1$ & $\mathrm{Fe}$ & 0,147528271 & 14,7 \\
$\mathrm{~K}$ & 0,036433488 & 3,6 & $\mathrm{Mn}$ & 0,044019265 & 4,4 \\
$\mathrm{Ca}$ & 0,189571461 & 18,9 & $\mathrm{Zn}$ & $(-) 0,186621451$ & $(-) 18,6$ \\
\hline
\end{tabular}


Para fins de avaliação em áreas novas, constitui-se uma ferramenta básica porque orienta os esforços dos tratos culturais, para estabelecer estratégias mais definidas com as variáveis mais importantes.

Outra vantagem deste procedimento é que o banco de dados pode ser alimentado constantemente, não esta fechado ao ingresso de novas observações. Pode-se desta maneira monitorar as mudanças das variáveis em sua ordem de contribuição com o rendimento e no tempo fazer paralelamente as mudanças dos tratos culturais e de outras atividades do processo produtivo, como seria no caso da cultura do plátano Hartón.

\subsection{Determinação da combinação ou balanço nutricional de referência}

$\mathrm{Na}$ visão clássica, estes valores seriam chamados de valores de referência. Entretanto omite-se seu uso porque lembra o nutriente de forma unilateral, simples, isolado, sem conexão com os concorrentes na avaliação nutricional e estimação do rendimento.

Portanto propõe-se "balanço nutricional de referência" porque um conjunto de variáveis que avaliam simultaneamente as propriedades físicas e químicas do solo e o estado nutricional da planta participam do processo de diagnóstico nutricional e de avaliação da fertilidade do solo, associados ao rendimento.

Desta maneira, já no inicio se obtive a calibração de todas em seu conjunto, indo alem dos princípios da diagnose foliar, ao alcançar as seguintes etapas: a) entre nutrientes do solo e folha com a produção, e b) entre nutriente no solo e nutriente na folha (Malavolta, 1999), restando só a comprovação.

O discutido anteriormente é possível pela propriedade dos componentes principais onde há uma relação funcional linear, que permite separar em classes a população estudada através dos pesos estimados pelo modelo de regressão do rendimento com as combinações lineares.

Nas tabelas 15 e 16 apresenta-se os valores das variáveis num balanço nutricional de referência (ou desbalanço se for o caso) estimados pelo modelo apresentado na 
Tabela 15. Balanço nutricional das variáveis do solo, por classes de rendimento.

\begin{tabular}{|c|c|c|c|c|}
\hline \multirow{3}{*}{$\frac{\text { Variáveis }}{\mathrm{pH}_{0}-40}$} & \multirow{3}{*}{$\frac{10,96-13,92}{6,62}$} & \multicolumn{2}{|c|}{ Classes em kg cacho $^{-1}$} & \multirow[b]{2}{*}{$>20 \mathrm{~kg}$} \\
\hline & & $14,00-17,90$ & $18,00-19,90$ & \\
\hline & & 6,68 & 6,56 & 6,64 \\
\hline $\mathrm{CE}_{0-20}$ & 0,302 & 0,313 & 0,404 & 0,417 \\
\hline $\mathrm{CE}_{21-40}$ & 0,240 & 0,264 & 0,311 & 0,404 \\
\hline $\mathrm{MO}_{0-20}$ & 13,80 & 16,5 & 16,9 & 19,4 \\
\hline $\mathrm{MO}_{21-40}$ & 8,8 & 10,7 & 11,2 & 13,8 \\
\hline a $0-40$ & 16,42 & 20,75 & 28,86 & 25,68 \\
\hline $\mathrm{L}_{0-40}$ & 62,11 & 59,15 & 54,34 & 56,31 \\
\hline $\mathrm{A}_{0-20}$ & 22,22 & 20,94 & 16,89 & 17,19 \\
\hline A $21-40$ & 20,58 & 18,69 & 15,83 & 17,41 \\
\hline $\mathrm{P}_{0-20}$ & 13,35 & 19,20 & 20,38 & 14,23 \\
\hline$P_{21-40}$ & 8,87 & 12,03 & 13,19 & 17,17 \\
\hline $\mathrm{K}_{0}-40$ & 0,913 & 1,16 & 1,15 & 1,36 \\
\hline $\mathrm{Ca}_{0}-40$ & 84,15 & 97,90 & 124,49 & 137,92 \\
\hline $\operatorname{Mg} 0-20$ & 15,59 & 17,13 & 15,63 & 15,25 \\
\hline $\operatorname{Mg}_{21-40}$ & 12,45 & 13,71 & 13,19 & 13,57 \\
\hline $\mathrm{S}_{0-40}$ & 202,4 & 92,16 & 344,95 & 468,54 \\
\hline $\mathrm{B}_{0-20}$ & 0,19 & 0,24 & 0,21 & 0,13 \\
\hline$B_{21-40}$ & 0,15 & 0,17 & 0,18 & 0,08 \\
\hline $\mathrm{Cu} 0-20$ & 1,76 & 1,69 & 1,64 & 1,64 \\
\hline $\mathrm{Cu}_{21-40}$ & 1,30 & 1,28 & 1,18 & 1,74 \\
\hline $\mathrm{Fe}_{0}-20$ & 61,15 & 50,96 & 66,27 & 64,54 \\
\hline $\mathrm{Fe}_{21}-40$ & 40,97 & 37,47 & 49,37 & 32,89 \\
\hline $\mathrm{Mn}_{0-20}$ & 9,78 & 8,51 & 7,20 & 10,82 \\
\hline $\mathrm{Mn}_{21-40}$ & 7,42 & 5,99 & 5,27 & 6,38 \\
\hline $\mathrm{Zn}_{0-20}$ & 1,16 & 1,44 & 1,70 & 3,28 \\
\hline $\mathrm{Zn}_{21-40}$ & 0,78 & 0,91 & 0,93 & 2,03 \\
\hline
\end{tabular}


Tabela 16. Balanço nutricional das variáveis da folha, por classes de rendimento.

\begin{tabular}{lcccc}
\hline \multirow{2}{*}{ Variáveis } & \multicolumn{4}{c}{ Classes em kg cacho-1 } \\
\hline $\mathrm{N}$ & $10,96-13,92$ & $14,00-17,90$ & $18,00-19,90$ & $>20 \mathrm{~kg}$ \\
$\mathrm{P}$ & 25,5 & 25,7 & $\mathrm{~g} \mathrm{~kg}^{-1}$ & 28,2 \\
$\mathrm{~K}$ & 1,95 & 1,88 & 2,10 & 2,06 \\
$\mathrm{Ca}$ & 44,4 & 41,9 & 39,4 & 42,8 \\
$\mathrm{Mg}$ & 7,76 & 6,83 & 5,87 & 5,23 \\
$\mathrm{~S}$ & 3,06 & 2,87 & 2,57 & 2,51 \\
& 2,97 & 2,11 & 1,57 & 1,48 \\
$\mathrm{~B}$ & & & $\mathrm{mg} \mathrm{kg}^{-1}$ & \\
$\mathrm{Cu}$ & 8,89 & 10,03 & 13,92 & 15,45 \\
$\mathrm{Fe}$ & 8,71 & 8,35 & 8,17 & 8,71 \\
$\mathrm{Mn}$ & 38,58 & 52,57 & 60,10 & 68,59 \\
$\mathrm{Zn}$ & 74,54 & 65,35 & 70,94 & 66,07 \\
$\mathrm{Mo}$ & 23,54 & 17,3 & 13,42 & 10,43 \\
$\mathrm{Na}$ & 1,27 & 1,52 & 1,63 & 1,13 \\
& 560 & 610 & 510 & 480 \\
\hline
\end{tabular}

tabela 4 e organizados nas seguintes classes de rendimento, a seguir: 10,96 - 13,92 kg cacho $^{-1}, 14,00-17,90 \mathrm{~kg} \mathrm{cacho}^{-1}, 18,00-19,90 \mathrm{~kg} \mathrm{cacho}^{-1}$ e $>20 \mathrm{~kg} \mathrm{cacho}^{-1}$.

$\mathrm{Na}$ tabela 15 nota-se que ainda aparecem as variáveis do solo: $\mathrm{pH}{ }_{0-40}, \mathrm{MO}_{21-40}$, $\mathrm{a}_{0-40}, \mathrm{~L}_{0-40}, \mathrm{Ca}_{0-40}, \mathrm{~S}_{0-40}, \mathrm{~B}_{0-20}, \mathrm{~B}_{21-40}, \mathrm{Fe}_{0-20}, \mathrm{Fe}_{21-40}$, e na tabela 16 , aparecem os nutrientes da folha: $\mathrm{B}, \mathrm{Mo}$ e Na.

Não obstante, como foi discutido no ponto 4.3.2, ainda que não participem da estimação do rendimento, poderiam contribuir na avaliação do balanço nutricional, desde que seja resolvido seus problemas relacionados com a falta da normalidade da distribuição dos dados. 


\subsection{Validação das variáveis no contexto do balanço nutricional de referência}

Num modo geral, os resultados da tabela 15 e 16, não concordam com os obtidos por Godefroy (1990), que constatou menor precisão dos resultados quando o amostragem foi realizada na faixa de aplicação de adubos, pelo fato da maior variabilidade. Não obstante, a variabilidade é expressa pelo procedimento deste trabalho.

Ainda numa visão geral, na tabela 16 constata-se uma diminuição da concentração de alguns nutrientes com o aumento do rendimento ( $\mathrm{K}, \mathrm{Ca}, \mathrm{Mg}, \mathrm{S}, \mathrm{Cu}, \mathrm{Mn}, \mathrm{Zn}, \mathrm{Mo}$ e Na), Ao respeito, Martin-Prével, 1984, assinalou que no caso da bananeira, pode ocorrer que um mesmo teor foliar, por exemplo no caso do nitrogênio corresponda-se a diferentes porcentagem do rendimento máximo (Efeito de Steenbjerg). Considerou indispensável atrelar a analises foliar com medidas do crescimento, na espera que uma concepção da amostragem mais quantificada forneça uma vista mas dinâmica de dados diretamente mais interpretáveis.

Agora, no detalhe de cada variável, na tabela 15: os conteúdos de matéria orgânica, sensivelmente crescentes com o rendimento, em ambas profundidades, concorda com Delvaux et al. (1986), autores que assinalam que solos argilosos e relativamente pobres em matéria orgânica tem menor aptitude bananeira.

Ademais, na tabela 15, Os conteúdos de areia (a), silte (L) e argila (A) coincidem com os reportados por Hedge \& Srinivas (1989) os quais expressam que em condições de altos potenciais mátricos, tem-se redução de peso fresco e a matéria seca dos frutos das bananas. Segundo Godefroy (1969); Avilán et al. (1979); Delvaux et al. (1986, 1990); Araya \& Blanco (2001), os melhores enraizamientos são observados em solos com melhores expectativas de boa drenagem.

$\mathrm{O}$ elemento $\mathrm{P}$ à profundidade de $0-20$, apresenta inconsistência com $\mathrm{o}$ rendimento, por outro lado de 21 - 40 vai desde o nível baixo até o patamar naior, sendo qualificado de baixo a alto por López \& Espinosa (1995) e Espinosa \& Belalcázar (2000). Isto evidencia as relações estreitas do fósforo no solo nesta profundidade e o rendimento e ainda mais se corresponde com a concentração foliar, das quais, vai nas classes de menor rendimento com concentrações embaixo do nível crítico $\left(2,0 \mathrm{~g} \mathrm{~kg}^{-1}\right.$, 
segundo Lahav \& Turner, 1983) até as classes de maior rendimento com concentrações acima do nível crítico.

O K no solo (Tabela 15), se qualifica de acordo a López \& Espinosa (1995) e Espinosa \& Balalcázar (2000) com nível baixo.

A média dos níveis de cálcio no solo foram de $101,88 \mathrm{mmol}_{\mathrm{c}} \mathrm{dm}^{3}$, concentração semelhantes á reportada por Delvaux et al. (1986), Twyford \& Walmsley (1973) e Warner \& Fox (1977), em solos bananeiros.

O elemento $\mathrm{Mg}$ no solo, não apresenta variações com o rendimento, tendo-se no patamar baixo, de acordo com López \& Espinosa (1995) e Espinosa \& Balalcázar (2000).

Em condições semelhantes de solos, ao respeito, Martin-Prével (1984) e Lahav (1995) comentam que altos níveis de $\mathrm{Ca}$ e $\mathrm{Mg}$ no solo, inibem a absorção de $\mathrm{K}$ na bananeira, mantendo-se no patamar de 31 a $34 \mathrm{~g} \mathrm{~kg}^{-1}$ na folha, nosso caso foi ao contrario, tendo-se ais elevado ainda, no patamar de 44,4 a $39,4 \mathrm{~g} \mathrm{~kg}^{-1}$ na folha de plátano, o qual acredita-se mais por efeito clonal, que nutricional

Martin-Prével (1984), assinalou que pelo efeito clonal, não significa necessariamente que cultivares diferentes reclamem, num mesmo solo e sob um mesmo clima, provisões de fertilizantes diferentes: cada um possui mecanismos de absorção e de translocação que podem compensar, não compensar, ou ultrapassar, estas diferenças de "necessidades internas".

O patamar de 44,4 a 39,4 $\mathrm{g} \mathrm{kg}^{-1} \mathrm{~K}$ na folha (tabela 16) não indica associação com o rendimento quando sua avaliação é feita com seus valores absolutos. Ao contrario, quando é feita pelo porcentual dos três elementos (tabela 17) aparecem incrementos do nutriente $\mathrm{K}$ e por outro lado, a diminuição dos nutrientes $\mathrm{Ca}$ e $\mathrm{Mg}$, pelo efeito da interação.

As percentagem da tabela 17, não coincidem com as ótimas apresentadas para a cultura da bananeira por Delvaux et al. (1986) de: $\mathrm{K}=52-60, \mathrm{Ca}=22-29$ e $\mathrm{Mg}=16-25$; García et al. (1976a) de $: \mathrm{K}=50-53,5, \mathrm{Ca}=25,5-31,5$ e $\mathrm{Mg}=14-17$.

Essas diferenças clonais, vai a ter profunda influencia na magnitude dos quocientes foliares $\mathrm{K} / \mathrm{Ca}$ e K/Mg (Tabela 18), onde são vistas diferenças em relação ao 
Tabela 17. Percentagem dos nutrientes $\mathrm{K}, \mathrm{Ca}$ e $\mathrm{Mg}$, em folhas de plátano Hárton, classificadas de acordo com a massa do cacho.

\begin{tabular}{|c|c|c|c|c|}
\hline \multirow[b]{2}{*}{ Nutriente $(\%)$} & \multicolumn{4}{|c|}{ 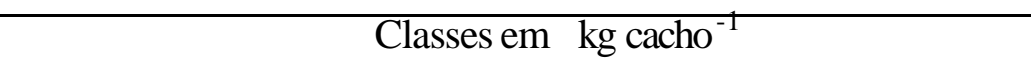 } \\
\hline & $10,96-13,92$ & $14,0-17,9$ & $18,0-19,9$ & $>20$ \\
\hline $\mathrm{K}$ & 80,4 & 81,2 & 82,4 & 84,8 \\
\hline $\mathrm{Ca}$ & 14,1 & 13,2 & 12,3 & 10,4 \\
\hline $\mathrm{Mg}$ & 5,5 & 5,6 & 5,4 & 4,9 \\
\hline
\end{tabular}

valores adequados reportados por García et al. (1976a) para bananas nos quocientes $\mathrm{K} / \mathrm{Ca}$ na faixa de 1,3 a 1,6 e K/Mg na faixa de 3,0 a 3,7.

Também é visto que o potássio aparece em maior proporção na classe de $>20 \mathrm{~kg}$.

Tabela 18. Quocientes K/Ca e K/Mg em folhas de plátano Hárton, classificados de acordo com a massa do cacho.

\begin{tabular}{|c|c|c|c|c|}
\hline \multirow[b]{2}{*}{ Quociente } & \multicolumn{4}{|c|}{ 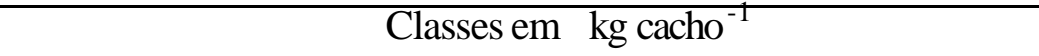 } \\
\hline & $10,96-13,92$ & $14,0-17,9$ & $18,0-19,9$ & $>20$ \\
\hline $\mathrm{K} / \mathrm{Ca}$ & 5,72 & 6,13 & 6,71 & 8,18 \\
\hline $\mathrm{K} / \mathrm{Mg}$ & 14,5 & 14,2 & 15,3 & 17,1 \\
\hline
\end{tabular}

Em relação aos teores de $\mathrm{K}$ e $\mathrm{Mg}$ no solo (tabela 15) e a partir do trabalho de Godefroy et al. (1965) (os quais também os determinaram em acetato de amônio, 1N, pH 7), são analisados como relações na tabela 19.

Os citados autores reportaram balanços adequados no quociente $\mathrm{K} / \mathrm{Mg}=0,6 \mathrm{em}$ bananeira, e é evidente a tendência crescente no balanço K/Mg na classe 10,96 - 13,92 $\mathrm{kg} \mathrm{cacho}^{-1}$, até a classe $>20 \mathrm{~kg} \mathrm{cacho}{ }^{-1}$. Balanço que poderia atingir valores semelhantes, sim os níveis de $\mathrm{K}$ são colocados no patamar de 2,9 mmol $_{\mathrm{c}} \mathrm{dm}^{3}$, nível esse considerado por Espinosa \& Belalcázar (2000) como critico para a cultura do plátano em solos das áreas plataneiras da Colômbia. 
Tabela 19. Quociente $\mathrm{K} / \mathrm{Mg}$ no solo, na cultura do plátano Hárton, classificados de acordo com a massa do cacho.

\begin{tabular}{lccccc}
\hline \multicolumn{2}{l}{ Quociente } & \multicolumn{5}{c}{ Classes em } & $\mathrm{kg} \mathrm{cacho}^{-1}$ \\
& & $10,96-13,92$ & $14,0-17,9$ & $18,0-19,9$ & $>20$ \\
\hline $\mathrm{K} / \mathrm{Mg}$ & $0-20$ & 0,19 & 0,22 & 0,24 & 0,28 \\
& $21-40$ & 0,23 & 0,28 & 0,28 & 0,33 \\
\hline
\end{tabular}

O N folhar (tabela 16) vai desde $25,5 \mathrm{~g} \mathrm{~kg}^{-1}$, teor abaixo do nível critico de $26,0 \mathrm{~g}$ $\mathrm{kg}^{-1}$ considerado por Lahav \& Turner (1983), até $28,2 \mathrm{~g} \mathrm{~kg}^{-1}$, teor que coincide com o nível associado com o maximo rendimento em bananas segundo Warner \& Fox (1977).

Quando o N é analisado como quociente, os resultados são mostrados na tabela 20.

Tabela 20. Quocientes K/N, N/P e K/P em folhas de plátano Hartón, classificados de acordo com a massa do cacho.

\begin{tabular}{|c|c|c|c|c|c|c|}
\hline \multirow[t]{2}{*}{ Quocient } & & \multicolumn{3}{|c|}{ Classes em $\mathrm{kg} \mathrm{cacho}^{-1}$} & \multirow{2}{*}{$\begin{array}{l}\text { Valor de } \\
\text { referência }\end{array}$} & \multirow[t]{2}{*}{ Autor } \\
\hline & $10,{ }^{96}-13,{ }^{92}$ & $14,,^{0}-17,{ }^{9}$ & $18,,^{0}-19,{ }^{9}$ & $>20$ & & \\
\hline \multirow[t]{5}{*}{$\mathrm{K} / \mathrm{N}$} & 1,74 & 1,63 & 1,39 & 1,57 & $1,5-1,7$ & Dumas, 1960 \\
\hline & & & & & $1,05-1,25$ & Martin-Prével et al., 1969 \\
\hline & & & & & $1,3-1,5$ & García et al., 1976b \\
\hline & & & & & 1,37 & Twyford \& Coulter, 1964 \\
\hline & & & & & 1,31 & Rodríguez, 1980 \\
\hline $\mathrm{N} / \mathrm{P}$ & 13,07 & 13,67 & 13,42 & 13,15 & $11,5-14$ & Martin-Prével et al., 1969 \\
\hline \multirow[t]{2}{*}{$\mathrm{K} / \mathrm{P}$} & 22,76 & 22,28 & 18,76 & 20,77 & $17,94^{(2)}$ & Rodríguez, 1980 \\
\hline & & & & & $11,38^{(3)}$ & Twyford \& Coulter, 1964 \\
\hline
\end{tabular}

(1) Bananeira.

(2) Nível inadequado: $15,58$.

(3) Nível inadequado: 8,90 
De acordo aos valores de referência de Dumas (1960), Martin-Prével et al. (1969), García et al. (1976b); Twyford \& Coulter (1964), Rodríguez (1980), evidencia-se os desbalanços $\mathrm{K} / \mathrm{N}$ nas classes de mais baixo rendimento.

$\mathrm{Na}$ mesma tabela, é visto que a relação N/P não apresenta fortes mudanças associadas ao rendimento e na relação $\mathrm{K} / \mathrm{P}$ põe em evidencia as diferencias clonais do alto conteúdo de $\mathrm{K}$ na folhas.

Quando é feita a relação do nitrogênio com o enxofre (tabela 21), é visto crescente tendência da relação N/S.

Tabela 21. Quociente N/S em folhas de plátano Hartón, classificados de acordo com a massa do cacho.

\begin{tabular}{|c|c|c|c|c|}
\hline \multirow[b]{2}{*}{ Quociente } & \multicolumn{4}{|c|}{ 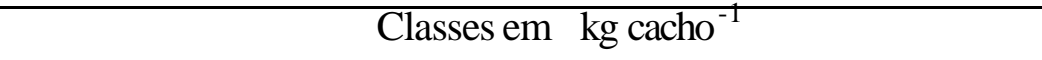 } \\
\hline & $10,96-13,92$ & $14,0-17,9$ & $18,0-19,9$ & $>20$ \\
\hline $\mathrm{N} / \mathrm{S}$ & 8,58 & 12,18 & 19,96 & 18,31 \\
\hline
\end{tabular}

Entretanto, por seu lado, a concentração de enxofre no solo aumenta con o rendimento (tabela 15), e é classificado de muito alto, de acordo aos limites de interpretação do Instituto Agronômico de Campina (1997) e na folha pelo contrario (tabela 16), diminui com o rendimento, sem cair abaixo de $1,0 \mathrm{~g} \mathrm{~kg}^{-1}$, nível critico para bananeira reportado por Warner \& Fox (1977), e dentro da faixa do máximo desenvolvimento relativo para o plátano de 1 a $3 \mathrm{~g} \mathrm{~kg}^{-1}$ (Lahav, 1995), ainda que, sob o nível critico de 2,3 $\mathrm{g} \mathrm{kg}^{-1}$ sugerido por Marchal et al. (1972).

Quanto os micronutrientes no solo (tabela 15), o boro se classificou de acordo aos limites de interpretação do Instituto Agronômico de Campinas (1997), nas quatro classes estudadas como baixo, entretanto na folha (tabela 16) não estaria dentro dos níveis deficitários de acordo a Lahav \& Tuner (1983).

O cobre, ferro, manganês e zinco classificam-se de alto para o Instituto Agronômico de Campinas (1997), ainda que o zinco mantivesse uma tendência crescente, nas duas profundidades, parece desejável rever os limites deste nutriente para 
a cultura do plátano, nas condições dos solos estudados, onde as constantes aplicações de adubos fosfatados e ademais, as elevadas concentrações nativas de cálcio, estão presentes.

Entretanto, na folha (tabela 17) dentre os micronutrientes o zinco só com um desempenho previsível e com base nos limites de interpretação de Lahav \& Turner (1983), se qualifica de adequado ao limite do déficit.

Uma explicação para a diminuição dos teores foliares do zinco, pode ser feita, pelos resultados de Lopez (1972), autor que usou a cevada como planta indicadora em solos com dose constante de zinco e crescentes aplicações de fosfatos e calagem. Ele observou que essas aplicações diminuíram os teores de zinco na planta, o que pode ser previsível nas condições dos solos deste estudo.

$\mathrm{O}$ molibdênio foliar, reflete os efeitos provocados pelo $\mathrm{pH}$. Altos valores de $\mathrm{pH}$ indicam teores de Mo elevados, os quais se classificam como adequados de acordo a Lahav \& Tuner (1983).

Inversamente, Gallo et al. (1974), em condições abaixo do $\mathrm{pH}$ 6, relataram teores de Mo ao redor de $0,2 \mathrm{mg} \mathrm{kg}^{-1}$, em bananeira.

\subsection{Quantificação do balanço nutricional}

O balanço nutricional zero, mediante esta proposta de interpretação dos resultados das analises de solos e folhas, é obtido a partir da média das variáveis padronizadas, como se explicou no itens 3.3.2.2.

Este fato implica que nas condições deste trabalho, onde se coletou ampla informação desde o mais baixo $\left(8,8 \mathrm{~kg} \mathrm{cacho}^{-1}\right)$ até o mais alto rendimento (29 kg cacho $^{-1}$ ), o balanço zero corresponde-se com a media do rendimento da subpopulação amostrada. Quando se observa o balanço nutricional na classes extremas, aparecem grandezas no balanço relacionadas mais com os desvios desde a media, que o relacionado propriamente com o balanço em sim. Por isso não é aplicável o conceito da literatura (Sumner, 1977a; 1977b; Monge et al., 1995; Montañez et al., 1995; Sanz et al., 
1999; Rodríguez et al., 1999; Bataglia et al., 2001) onde a maior desbalanço nutricional, será indicio de menor rendimento.

O conceito assinalado, só é aplicável em condições, onde exista a possibilidade que a média da subpopulação amostrada e o rendimento medio sejam da subpopulação excepcional o de mais alto rendimento.

Então, para resolver o assunto, nas condições desta pesquissa, a solução estriba-se na possibilidade de medir ou quantificar o balanço nutricional a partir do calculo da contribuição de cada variável (vistas nas tabelas 13 e 14).

Assim, quando qualquer amostra a avaliar tenha os mesmos valores da média da subpopulação amostrada, a contribuição iguala-se a zero (tabela 22) e estima-se logicamente o rendimento médio da população de $15,4257 \mathrm{~kg}^{\text {cacho }}{ }^{-1}$. Por tanto a interpretação é que o balanço zero é o rendimento médio e não o mais alto rendimento.

Tabela 22. Contribuição das variáveis do solo e da folha no modelo de regressão do rendimento com as combinações lineares em: A média da subpopulação amostrada e na classe de $>20 \mathrm{~kg}_{\text {cacho }}{ }^{-1}$ na cultura do plátano Harton.

\begin{tabular}{|c|c|c|c|}
\hline \multirow{3}{*}{ Rendimento esperado } & \multirow{3}{*}{$\begin{array}{l}\text { Media da subpopulação } \\
15,425 \mathrm{~kg} \mathrm{cacho}^{-1} \\
\text { Desvio }\end{array}$} & \multicolumn{2}{|c|}{${\text { Classe de }>20 \mathrm{~kg} \mathrm{cacho}^{-1}}^{-1}$} \\
\hline & & \multicolumn{2}{|c|}{$20,842 \mathrm{~kg} \mathrm{cacho}^{-1}$} \\
\hline & & Desvio $\mathrm{x}$ & x100 \\
\hline Variáveis & & Contribuição & \\
\hline $\mathrm{CE}_{0-20}$ & 0 & $-0,099743699$ & (-) 9,9 \\
\hline $\mathrm{CE}_{21-40}$ & 0 & $-0,287400095$ & (-) 28,7 \\
\hline $\mathrm{MO}_{0-20}$ & 0 & $-0,121140107$ & (-) 12,11 \\
\hline $\mathrm{P}_{0-20}$ & 0 & 0,008325293 & 0,83 \\
\hline$P_{21-40}$ & 0 & $-0,001557343$ & $(-) 0,15$ \\
\hline $\mathrm{K}_{0-40}$ & 0 & $-0,047537344$ & $(-) 4,7$ \\
\hline $\mathrm{Mg}_{0-20}$ & 0 & $-0,013151492$ & $(-) 1,3$ \\
\hline $\mathrm{Mg}_{21-40}$ & 0 & $-0,005565191$ & (-) 0,55 \\
\hline
\end{tabular}


Tabela 22. Contribuição das variáveis do solo e da folha no modelo de regressão do rendimento com as combinações lineares em: A média da subpopulação amostrada e na classe de $>20 \mathrm{~kg}$ cacho $^{-1}$ na cultura do plátano Harton.

\begin{tabular}{|c|c|c|c|}
\hline \multirow{3}{*}{ Rendimento esperado } & \multirow{3}{*}{$\begin{array}{l}\text { Media da subpopulação } \\
15,425 \mathrm{~kg} \mathrm{cacho}^{-1} \\
\text { Desvio }\end{array}$} & \multicolumn{2}{|c|}{ Classe de $>20 \mathrm{~kg} \mathrm{cacho}^{-1}$} \\
\hline & & \multicolumn{2}{|c|}{$20,842 \mathrm{~kg} \mathrm{cacho}^{-1}$} \\
\hline & & Desvio $\mathrm{x}$ & $\mathrm{x} 100$ \\
\hline Variáveis & & Contribuição & \\
\hline$\overline{\mathrm{AA}_{0-20}}$ & 0 & $-0,208015357$ & $(-) 20,80$ \\
\hline $\mathrm{AA}_{21-40}$ & 0 & $-0,061480094$ & (-) 6,14 \\
\hline $\mathrm{Mn}_{0-20}$ & 0 & 0,043641012 & 4,36 \\
\hline $\mathrm{Mn}_{21-40}$ & 0 & 0,003906558 & 0,39 \\
\hline $\mathrm{Cu}_{0-20}$ & 0 & 0,020838846 & 2,08 \\
\hline $\mathrm{Cu}_{21-40}$ & 0 & 0,074225465 & 7,42 \\
\hline $\mathrm{Zn}_{0-20}$ & 0 & $-0,502038899$ & (-) 50,20 \\
\hline $\mathrm{Zn}_{21-40}$ & 0 & 0,159411316 & 15,94 \\
\hline$S$ (folha) & 0 & $-1,646060281$ & (-) 164,6 \\
\hline$N$ (folha) & 0 & $-0,113741459$ & (-) 11,37 \\
\hline $\mathrm{P}$ (folha) & 0 & 0,041025705 & 4,10 \\
\hline K (folha) & 0 & 0,02364761 & 2,36 \\
\hline $\mathrm{Ca}$ (folha) & 0 & $-0,453734386$ & (-) 45,37 \\
\hline Mg (folha) & 0 & 0,199153065 & 19,91 \\
\hline $\mathrm{Cu}$ (folha) & 0 & $-1,013370985$ & (-) 101,33 \\
\hline $\mathrm{Fe}$ (folha) & 0 & 0,043263963 & 4,32 \\
\hline Mn (folha) & 0 & $-0,413344331$ & (-) 41,33 \\
\hline Zn (folha) & 0 & 0,03347066 & 3,34 \\
\hline
\end{tabular}

No mesmo ordem de idéias, quando qualquer amostra a avaliar tenha os mesmos valores da subpopulação de mais alto rendimento e como neste caso, de $20 \mathrm{~kg}$ cacho $^{-1}$, a contribuição terá os valores dos desvios com respeito á média da subpopulação, vezes a 
contribuição de cada variável (tabelas 22). Portanto, a interpretação é que o balanço tem a magnitude dos desvios com respeito á media da subpopulação vezes a contribuição de cada variável é o mais alto rendimento, com media de $20,842 \mathrm{~kg}$ cacho $^{-1}$.

Para uma melhor visão dos números, na coluna x100 da tabela 22, aparecem as contribuições vezes 100 .

A interpretação agora esta facilitada, faltando só comparar e conferir o obtido:

- O maior efeito absoluto das variáveis do solo sobre o rendimento foi do zinco á profundidade de $0-20 \mathrm{~cm}$, a condutividade elétrica á profundidade de $21-40 \mathrm{~cm}$ e da argila á profundidade de $0-20 \mathrm{~cm}$.

- O maior efeito absoluto das variáveis da folha sobre o rendimento foi do enxofre, cobre, cálcio e manganês.

O restante é questão de integrar a interpretação desses resultados aos tratos culturais da cultura, buscando atingir nas lavouras com problemas nutricionais os níveis dos nutrientes no solo e na folha semelhantes aos obtidos na classe de $>20 \mathrm{~kg} \mathrm{cacho}^{-1}$, planejando primeiramente mudar as condições que afetam no solo ao zinco, condutividade elétrica e a argila, e na folha o enxofre, cálcio e cobre, pelo fato que pequenas mudanças dessas variáveis têm fortes efeitos no rendimento. 


\section{CONCLUSÕES}

De acordo com os resultados, para a cultura do plátano Hartón, nas condições assinaladas conclui-se o seguinte:

1 A analises multivariada dos componentes principais, apresentou melhor estimação do rendimento ao considerar o maior número de variáveis, que o modelo de regressão múltipla e as médias da subpopulação excepcional.

2 Não são necessários valores de referência para poder fazer o diagnostico nutricional e a avaliação da fertilidade do solo mediante o uso da analises multivariada pelos componentes principais.

3 A analises multivariada pelas análises dos componentes principais, vai além do uso de valores de referência isolados, pois permite entre todas as variáveis estudadas determinar e utilizar como referência, o balance nutricional delas.

4 Obtendo-se um diagnóstico ao inicio do estudo ou avaliação, fornece-se a base para poder proceder a desenhar a estratégia dos tratos culturais a aplicar posteriormente, com a possibilidade de monitorar nutricionalmente a evolução da cultura, sem necessidade de valores de referência.

5 Estas discussões permitem apresentar o procedimento acima discutido, como uma proposta de interpretação dos resultados de analises de solos e folhas. 


\section{REFERÊNCIAS BIBLIOGRÁFICAS}

ADETUNJI, M. T. Optimun sample size and sampling depth for soil nutrient analysis of some tropical soils. Communication in Soil Science and Plant Analysis, v. 25, n. 3/4, p.199-205, 1994.

AMUNDSON, R.; KOEHLER, F. Utilization of DRIS for diagnosis of nutrient deficiencies in winter wheat. Agronomy Journal, v. 79, p. 472-476, 1987.

ARAYA, M.; BLANCO, F. Changes in the stratification and spatial distribution of the Banana (Musa AAA cv. Grand Naine) root systems of poor, regular and good developed plants. Journal of the Plant Nutrition, v. 24, n. 11, p. 1679-1693, 2001.

ARNOLD, R.; JETT, J.; ALLEN, H. Identification of nutritional influences on cone production in fraser Fir. Soil Science Society of America Journal, v. 56, p. 586591, 1992.

ANGELES, D.M.; SUMNER, M. E.; BARBOUR, N. W. Preliminary nitrogen, phophorus and potassium DRIS norms for pineapple. HortScience, v. 25, p. 652$655,1990$.

ANGELES, D.M.; SUMNER, M. E.; LAHAV, E. Preliminary DRIS norms for bananas. Journal of Plant Nutrition, v. 16, p. 1059-1070, 1993. 
ALKOSHAB, O.; RGHETTI, T.; DIXON, A. Evualation of DRIS for judging the nutritional status of hazelnuts. Journal of the American Society for Horticultural Science, v. 113, p. 643-647, 1998.

ALVAREZ CAJAS, V. M. Tamaño de muestra: Procedimientos usuales para su determinación. Chapingo, México. 1988. 161p. Tesis (Maestro en Ciencias)Colegio de Posgraduados.

AVILÁN, L.; MENESES, L.; SUCRE, R.; ORTA, C.; SANGLE, O. Distribución del sistema radical del Banano "Pigneo gigante"bajo cuatro sistemas de manejo de suelo. Agronomía Tropical, v. 29, n. 4, p. 229-312, 1979.

AWASTHI, R. P.; SHARMA, S. K.; BHUTÁNI, V. P. Diagnosis and recommendation integrated system (DRIS) norms peach (Prunus persica L.) cv. July Elberta in Himacal Pradesh. The Indian Journal of Horticulture, v. 57, n. 4, p. 277-280, 2000 .

AWASTHI, R.P.; BHUTANI, V.P.; SHARMA, J.C.; KAITH, N.S. Mineral nutrient status of apple orchards in shimla district of Himachal Pradesh. The Indian Journal of Horticulturae, v. 55, p. 314-322, 1998.

BATAGLIA, O. C. DRIS-CITROS: Uma alternativa para availar a nutrição das plantas. Laranja, v. 10, n. 2, p. 565-576, 1989.

BATAGLIA, O. C.; SANTOS, W. R. dos. Efeito do procedimento de calculo e da população de referência nos índices do Sistema Integrado de Diagnose e Recomendação (DRIS). Revista Brasileira de Ciência do Solo., v. 14, p. 339-344, 1990. 
BATAGLIA, O.C.; SANTOS, W.R.; QUAGGIO, J.A. Reference populations for evaluation of the nutritional status of coffee by DRIS. In: PLANT NUTRITION FOOD SECURYITY AND SUSTAINABILITY OF AGRO-ECOSYSTEMS, Bonn, Alemania, 2001. Plant nutrition food security and sustainability of Agroecosystems . Netherlands: Kluwer Academic, 2001. p. 728 - 729.

BATES, T. E. Factor affecting critical nutrient concentrations in plants and their evaluation. A review. Soil Science, v. 112 n. 2, p. 115-234, 1971.

BEAUCLAIR, E. G. F de. Relações entre algumas propriedades químicas do solo e a produtividade da cana de açucar (Saccharum spp.), através de regressão linear multipla. Piracicaba, 1991. 90 p. Dissertação (mestrado.) - Escola Superior de Agricultura “Luiz de Queiroz”, Universidade de São Paulo.

BEAUFILS, E.R. Research for rational exploitation of Hevea brasiliensis using a physiological diagnosis based on mineral analysis of various parts of plant. Fertilite v. 6, n. 3, p. 27-37, 1957.

BEAUFILS, E. R. Diagnosis and recommendation integrated system (DRIS). Soil Science Bulletin, v. 1, n. 1, p. 1-132, 1973.

BEAUFILS, E. R. Plant/ Soil/ Environment calibration (D.R.I.S.). In: INTERNATIONAL COLLOQUIM ON THE CONTROL OF PLANT NUTRITION, 4., Gent, 1976. Gent: A. Cottenie., 1976. v. 1. p. 21-36.

BELL, P.; HALLMARK, W.; SABBE, W.; DOMBECK, D. Diagnosing nutrient deficiencies in soybean, using M-DRIS and critical nutrient level procedures. Agronomy Journal, v. 87, p. 859-865, 1995. 
BEVERLY, R. B.. Comparison of DRIS and alternative nutrient diagnostic metods for soybean. Journal of Plant Nutrition, v. 10, n. 8, p. 901-920, 1987.

BEVERLY, R.; WORLEY, R. Preliminary DRIS diagnostic norms for pecan. HortScience,.v. 27, p. 271-274, 1992.

BOX, G. E. P.; COX. D. R. An analysis of transformation. Journal of Royal Statistics Society. Series B, v. 26, p. 211-234, 1964.

BOWEN, J. Comparative DRIS and critical concentration interpretation of papaya tissue analysis data. Tropical Agriculture, v. 69 n. 1, p. 63-67, 1990.

BURKE, M.; RAINAL, D. Liming influences growth and nutrient balances in sugar maple (Acer saccharum) seedling on an acidic forest soil. Environmental and Experimental Botany, v. 39, p.105-116, 1998.

CALDWELL, J.; SUMNER, M. E.; VAVRINA, C. S. Development and testing of preliminary foliar DRIS norms for onions. HortScience, v. 29, p. 1501-1504, 1994.

CARMELlO, Q. A. DE C. Regressão lineal multipla aplicada à seleção de dados das analyses químicas de terra e de folhas, que mais relacionam às produtividades de amendoim e milho. Piracicaba, 1991. 94 p. Tese (Livre-Docência) - Escola Superior de Agricultura 'Luiz de Queiroz", Universidade de São Paulo.

CLARK, H.E.; POWERS, W.L. Leaf analysis as an indicator of potassium requirement of cane fruits. Plant Physiology, v. 20, p. 51-61, 1945.

CLINE, M. G. Principles of soil sampling. Soil Science, v. 58. p. 275-288, 1944. 
CARON, J.; PARENT, L. E Derivation and assessment of DRIS norms for greenhouse tomatoes. Canadian Journal of Plant Science, v. 69, p. 1027-1035, 1989.

CARON, J.; PARENT, L.; GOSSELIN, A. Effect of nitrogen and salinity levels in the nutrient solution on the DRIS diagnosis of greenhouse tomato. Communications in Soil Science and Plant Analysis, v. 22, p. 879-892, 1991.

CERDÁ, A.; NIEVES, M.; MARTÍNEZ, V. An evaluation of mineral analysis of Verna lemons by DRIS. Communications in Soil Science and Plant Analysis, v. 26, n. 11/12, p. 1697-1707, 1995.

COSTA NETO, P. L. Estatística. São Paulo:Edgard Blücher, 1999. 264p.

CRESTE, J. E. 1996. Uso do DRIS na avaliação do estado nutricional do limoneiro siciliano. Botucatu, 1996. 120 p. Tese (Doutoramento)-Faculdade de Ciências Agronômicas, Universidade Estadual Paulista. ”Julio de Mesquita Filho".

CRESTE, J.; NAKAGAWA, J. Estabelecimento do DRIS para a cultura do limoeiro em função da análise foliar. I. Calculo de normas. Revista Brasileira de Fruticultura, v. 19, n. 3, p.297-305, 1997.

COCHRAN, W. Técnicas de amostragem Rio de Janeiro:Editora Fundo de cultura, 1965. 553p.

DARA, S.; FIXEN, P.; GELDERMAN, R. Sufficiency level and diagnosis and recomendation integrated system approaches for evaluating nitrogen status of corn. Agronomy Journal, v. 84, p. 1006-1010, 1992.

DELVAUX, B. SOILS. N: GOWEN, S. Bananas and Plantains. New York: Chapman \& Hall, 1995. cap. 9, p. 231-257. 
DELVAUX, B.; PERRIER, X.; GUYOT, PH. Diagnostic de la fertilité de systèmes culturaux intensifs en bananeraies à la Martinique. Fruits, v. 45, n. 3, p. 223-236, 1990.

DELVAUX, B.; LASSOUDIERE, A.; PERRIER, X.; MARCHAL, J. Une mèthodologie d'ètude des relations sol-plante-techineques culturales par enquête diagnostic. Fruits, v. 41, n. 6, p. 359-370, 1986.

DOREL, M.; PERRIER, X. Influence de milieu et des techniques culturales sur la productivité des bananeiras de Guadaloupe. Enquête - diagnostic. Fruits, v. 45, n. 3, p. $237-244,1990$.

DOW, A. I.; ROBERTS, S. Proposal: Critical nutrient ranges for crop diagnosis. Agronomy Journal, v. 74, p. 401-403, 1982.

DUMAS, J. Controle de nutrition de qualques bananeraies dans trois territoires Africains. Friuts, v. 15, p. 277-290, 1960.

ESPINOSA, J.; BELALCÁZAR, S. Fertilization of plantain in high densities. Better crops International, v. 14, n. 1, p. 16-19, 2000.

ESTEBAN, E.; AGUILAR, A. Analisis foliar en cultivos hortícolas. I. Patata. In: INTERNATIONAL COLLOQUIM ON THE CONTROL OF PLANT NUTRITION, 4., Gent, 1976. Proceeding • Gent: A. Cottenie, 1976. v. I. p. 219227.

EVANYLO, G.; SUMNER, M. E.; LETSCH, W. S. Preliminary development and testing of DRIS soil norms for soybean production. Communications in Soil Science and Plant Analysis, n. 18, p. 1355-1377, 1987. 
FAILlA, O.; BOGONI, M.; PORRO, D.; STRINGARI, G. Soil and leaf analysis: Efect pedo-climatic, cultural, and genetics factor on their calibration and interpretation. Acta Horticulturae, v. 448, p. 225-239, 1997.

FITTS, J.; NELSON, W. The determination of lime and fertilizer requeriments of soil through chemical tests. Advance in Agronomy, n. 8, p. 241-282, 1956.

GALlO, J.R.; HIROCE, R.; BATAGLIA, O.C.; FURLANI, P.R.; FURLANI, A.M.C.; RAMOS, M.T.B.; MOREIRA, R.S. Sutuação nutricional de bananais do Estado de São Paulo. Ciência e Cultura, v. 26, n. 4, p. 355-359, 1974.

GARCÍA, R.; GUIJARRO, R.; DÍAZ, B. Modificación del estado nutricional del banano por efecto del potasio en suelos rojos de Cuba, relación con el rendimiento y control dela fertilización. In: INTERNATIONAL COLLOQUIM ON THE CONTROL OF PLANT NUTRITION, 4., Gent, 1976. Proceeding. Gent: A. Cottenie, 1976a. v. 2. p. $577-584$.

GARCÍA, R.; GUIJARRO, R.; DÍAZ, B. Efecto del exceso de nitrógeno sobre el estado nutricional y rendimientos del banano en suelos rojos de Cuba. In: INTERNATIONAL COLLOQUIM ON THE CONTROL OF PLANT NUTRITION, 4., Gent, 1976. Proceeding. Gent: A. Cottenie, 1976b. v. 2. p. 585591.

GODEFROY, J. Le dèveloppement des racines do bananier dans divers sols: Relation avec la fertilité v. 24, n. 2, p. 101-104, 1969.

GODEFROY, J. Etude de l'é chantillonage du sol em bananeraies de Martinique. Fruits, v.45, n.1, p. 3-7, 1990. 
GODEFROY, J.; MONTAGUT, G.; DORMOY, M. Essais sol-plante sur Bananiers. Fruits, v. 20, n. 6, p. 274-281, 1965.

GOH, K.; MALAKOUTI, E.M. Preliminary nitrogen, phosphorus, potassium, calcium and magnesium DRIS norms and indexes for apple orchards in Canterbury, NewZeland. Communications in Soil Science and Plant Analysis, v. 23, p. 1371-1385, 1992.

HADDAD, O.; MACHADO, W.; DEL VALLE, R. Un índice para evaluar el vigor en las musaceas comestibles para el bosque seco tropical. Fruits, v. 49, n. 1, p. 47-60, 1994.

HALLMARK, W.; BEVERLY, R.; SUMNER, M. E.; DEMOOY, C.; MORRIS, H.; PESEK, J.; FONTENOT.. Soybean phosphorus and potassium requeriment evaluation by three M-DRIS data bases. Agronomy Journal, v. 82, p. 323-328, 1990.

HAMEL, CH.; FURLAN, V.; SMITH, D. Mycorrhizal effects on interespecific plant competition and nitrogen transfer in Legume-grass mixtures. Crop Science, n. 32, p. 991-996, 1992.

HARTZ, T. K.; MIYAO, E. M.; VALENCIA, J. G. DRIS evaluation of the nuritional status of processing tomato. Hortscience, v. 33, n. 5, p. 830-832, 1998.

HEGDE, D.M.; SRINIVAS, K. Effect of soil moisture stress on fruit growth and nutrient accumulatin in Banana cultivar 'Robusta'. Fruits, v. 44, n. 3, p. 135-138, 1989. 
HOCKMAN, J.; BURGER, J.; SMITH, D. A DRIS application to fraser fir christmas trees. Communications in Soil Science and Plant Analysis, v. 20, n. 3/4, p. 305318, 1989.

HOLLAND, D.A. The interpretation of leaf analysis. Journal of Horticultural Science, v. 41, p. 311-329, 1966.

HOLLAND, D.A Component analysis: An aid to the interpretation of data. Experimental Agriculture, v. 5, p. 151-164, 1969.

INSTITUTO AGRONÓMICO CAMPINAS. Recomendações de adubação e calagem para o Estado de São Paulo. 2 ed. Campinas;Instituto Agronómico/Fundação IAC, 1997. 285p.

JOHNSON, R. A.; WICHERN, D. W. Applied multivariate statistical analysis. Madison:Prentice Hall International., 1995. 607 p.

JONES, C.; BOWEN, J. Comparative DRIS and crop log diagnosis of sugarcane tissue analysis. Agronomy Journal,v. 73, p. 941-944, 1981.

JONES, M.; SINCLAIR, A. Aplication of DRIS to White clover based pastures. Communications in Soil Science and Plant Analysis, v. 22, p. 1895-1918, 1991.

JONES, C. Proposed modifications o the diagnosis and recomendation integrated system (DRIS) for interpreting plant analyse. Communications in Soil Science and Plant Analysis, v. 12, n. 8, p.785-794, 1981. 
KIJESWSKI, J.; COLINA, J.; SLEEGMAGER, P.; MADERO, .O.; BOJANOWSKI, Z. Estudio de suelos semidetallado, sector rio Mucujepe - rio Escalante. Zona Sur del Lago de Maracaibo. Maracaibo:MARNR, 1981. 278 p. (Serie Informes Técnicos Zona 5-IT-156.)

LACHICA, M. Estudio sobre la determinación de boro en plantas con azometina-H. In: INTERNATIONAL COLLOQUIM ON THE CONTROL OF PLANT NUTRITION, 4., Gent, 1976. Proceeding. Gent: A. Cottenie, 1976. v. 2. p. 53-61.

LAHAV, E. Banana Nutrition. In: GOWEN, S. (Ed.) Bananas and Hantains. London: Chapman \& Hall, 1995. cap. 10, p. 259-316.

LAHAV, E.; TURNER, D. W. Fertilising for high field banana. Berne/ Switzerland: International Potash Institute, 1983. 62 p. ( IPI-Bulletin, 7.)

LANGENEGGER, W.; DU PLESSIS, S.F. The deterination of the nutrional status of `dwarf Cavendish’ bananas in South Africa. Fruits, v. 32, n. 12, p. 711-724, 1977.

LEANDRO, W. M.; ALMEIDA NETO, J. X.; OLIVEIRA DE, J. P.; OLIVEIRA, S. A.; CHITOLINA, J. C. Sistema integrado de diagnostico e recomendação para a cultura da soja. I. Obtenção dos níveis de suficiência para nutrientes nas analises foliares e de terra (compat disc). In: CONGRESO LATINOAMERICANO DE LA CIENCIA DEL SUELO, 14., Temuco, Chile, 1999. Sociedad Chilena de la Ciencia del Suelo. Temuco, Chile:SCCS/SLCS, 1999.

LETZSCH, W. S.; SUMNER, M. E. Effect of population size and yield level on selection of Diagnosis and Recommendation Integrated System (DRIS) norms. Communications in Soil Science and Plant Analysis, v. 15, p. 997-1006, 1984. 
LÓPEZ G O. E Contribuição ao estudo das relações entre zinco e o fósforo na nutrição das plantas. Piracicaba, 1972. 44 p. Tese (Doutorado) - Escola Superior de Agricultura “Luiz de Queiroz”, Universidade de São Paulo.

LÓPEZ, M. A.; ESPINOSA, J. Manual de nutrición y fertilización del banano. Quito, Ecuador:INPOFOS,. 1995. 82 p.

LOZANO, F. C.; HUYNH, K. D. Foliar diagnosis of sugar maple decline by DRIS. Communications in Soil Science and Plant Analysis, v. 20, n. 17/ 18, p. 18951914, 1989.

LUCENA, J. J. Methods of diagnosis of mineral nutrition of plant. A critical review. Acta Horticulturae, v. 448, p. 179-192, 1997.

MACKAY, D. C.; CAREFOOT, J. M.; ENTZ, T Evaluation of the DRIS for assessing the nutritional status of potato (Solanum tuberosum L.). Communications in Soil Science and Plant Analysis, v. 18, n. 12, p. 1331-1353, 1987.

MACY, P. The quantitative mineral requeriments of plants. Plant Physiology, v. 11, p. 749-764, 1936.

MAMARIL, C. P. International and national cooperation in long-term coordinated schemes of experimentation on fertilizer. In: COLLOQUIUM OF THE INTERNATIONAL POTASH INSTITUTE HELD, 19., Bangkok, 1985. Potassium in the Agricultural systems of the humid tropics. Bern/Switzerland:International Potash Institute, 1985. p. 335-344.

MALAKOUTI, M. Determining of the diagnostic norms for corn on the calacareous soils of Iran. Communications in Soil Science and Plant Analysis, v. 23, n. 17/ 20, p. 2687-2695, 1992. 
MALAVOLTA, E. A diagnose foliar - passado, presente e futuro (compact disc). In: SIMPÓSIO SOBRE MONITORAMENTO NUTRICIONAL PARA A RECOMENDAÇÃO DA ADUBAÇÃO DE CULTURAS, Piracicaba, 1999. Anais. Piracicaba: POTAFOS/PPI, 1999.

MALAVOLTA, E.; OLIVEIRA, S. A.; VITTI, G. The use of diagnosis recomendation integrated system (DRIS) to evaluate the nutritional status of healthy and blight affected citrus trees. In: OPTIMIZATION OF PLANT NUTRITION, Optimization of Plant Nutrition. Netherlands: Kluwer Academic , 1993. p. 157-159.

MALAVOlTA, E.; VITTI, G.; OLIVEIRA, S. A. DE. Avaliação do estado nutricional das plantas. Principios e aplicações. 2 ed. Piracicaba: POTAFOS, 1997. 320 .

MARTIN-PRÉVEL， P.; LACOEUILHE， J. J.; MARCHAL， J. Orientations du diagnostic foliare de bananier. Fruits, v. 24, n. 3, p. 153-161, 1969.

MARCHAL, J.; MARTIN-PEVEL, P.; MELIN, Ph. Le soufre et le bananier. Fruits, v. 27, n. 3 , p. $167-177,1972$.

MARTIN-PRÉVEL, P. La nutrition minerale du bananier dans le monde. Primière partie. Fruits., v. 35, n. 9, p. 503-518, 1980a.

MARTIN-PRÉVEL, P. La nutrition minerale du bananier dans le monde. Deuxiéme partie. Fruits., v. 35, n. 10, p. 583-593, 1980 b.

MARTIN-PRÉVEL, P. Exigências nutricionais da bananicultura. In: SIMPOSIO BRASILEIRO SOBRE BANANICULTURA, 1., , Jaboticabal, 1984. Anais. Jaboticabal: UNESP, 1984. p. 118-134. 
MELSTED, S. W.; MOTTO, H. L.; PECK, T. R. Critical plant nutrient composition values useful in interpreting plant análisis data. Agronomy Journal, v. 61, p. 17-20, 1969.

MONGE, E.; MONTAÑEZ, L.; Val, J.; Sanz, M. A comparative study of the DOP and the DRIS Methods, for evaluating the nutritional status of peach trees. Acta Horticulturae, v. 383, p. 191-199, 1995.

MONTAÑEZ, L.; MONGE, E.; VAL, J.; SANZ, M. Interpretative possibilities of plant analysis by the DOP index. Acta Horticulturae, v. 383, p. 165-171, 1995.

NAVA, C. El plátano. Su cultivo en Venezuela. Maracaibo, Venezuela: Astro Data, 1997. 136p.

NAVVABZDEH, M.; MALAKOUTI, M. Development of DRIS norms for potato in the calcareous soils of Iran. Journal of Plant Nutrition v. 16, p. 1409-1416, 1993.

NELSON, L. Estadística en la investigación del uso de fertilizantes. Quito, Ecuador: INPOFOS, 1999. 66p.

NOGUEIRA DA COSTA, A; BRAGANÇA, S. M.; DESSAUNE, N. Uso do DRIS na avaliação nutricional do cafeeiro Conilom (Coffea canéfora) no estado do Espírito Santo. (compac disc). In: CONGRESSO BRASSILEIRO DE CIENCIA DO SOLO, 16., Rio de Janeiro, 1997. Anais. Rio de Janeiro:SBSC, 1997.

NEEDHAM, T. D.; BURGER, J. A.; ODERWALD, R. G. Relationship between Diagnosis And Recommendation Integrated System (DRIS) optima and foliar nutrient critical levels. Soil Science Society of./ America Journal, v. 54, p. 883886, 1990. 
OLIVEIRA, S. A. Obtenção do níveis ótimos de nutrientes na planta e no solo por meio do DRIS. (compact disc). In: SIMPÓSIO SOBRE MONITORAMENTO NUTRICIONAL PARA A RECOMENDAÇÃO DA ADUBAÇÃO DE CULTURAS, Piracicaba, 1999. Anais. Piracicaba:POTAFOS/PPI, 1999.

OVALLES, F.A.; COLLINS, M.E. Variability of Northwest Florida soils by principal component Analysis. Soil Science Society of America Journal, v. 52, p. 1430$1435,1988$.

PARENT, L.E.; GRANGER, R. L. Derivation of DRIS norms from a high density apple orchard established in the Quebec Appalachian Mountains. Journal of the American Society for Horticultural Science, v. 114, p. 915-919, 1989.

PARENT, L.E.; DAFIR, E. A theoretical concept of compositional nutrient diagnosis. Journal of the American Society for Horticultural Science, v. 117, n. 239-242, 1992.

PARENT, L.E.; KARAM, A.; VISSER, S.A Compositional nutrient disgnosis of the greenhouse Tomato. HortScience, v. 28, n. 10, p.1041-1042, 1993.

PARENT, L.E.; CAMBOURIS, A.N.; MUHAWENIMANA, A. Multivariate diagnosis of nutrient imbalance in potato crops. Soil Science Society of America Journal, v. 58, p. $1432-1438,1994$ a.

PARENT, L.E.; ISFAN, D.; TREMBLAY, N.; KARAM, A. Multivariate nutrient diagnosis of the carrot crop. Journal of the American Society for Horticultural Science, v. 119, n. 3, p. 420-426, 1994 b.

PARENT, L.E.; POIRIER, M.; ASELIN, M. Multnutrient diagnosis of nitrogen status in plants. Journal of plant nutrition, v. 18, n. 5, p. 1013-1025, 1995. 
PIMENTEL GOMES, F.; CONAGIN, A. Experimentos de adubação: Planejamento e análise estatística. In: OLIVEIRA, A. J. DE; GARRIDO, W. E.; ARUJO, J. D.; LOURENÇO, S.(Ed.). Metodos de pesquisa em fertilidade do solo. Brasilia: EMBRAPA, 1991. cap. 4, p.103-188.

PREVOT, P.; OLLAGNIER, M. Método de utilización do diagnóstico foliar. Fertilité, v. 2, p. 3-12, 1957.

RAFTHON, R. A.; BURGER, J. A. Diagnosis and recomendation integrated system modifications for frases christmas trees. Soil Science Society of American Journal, v. 55, p. 1026-1031, 1991.

RAGHUPATHI, H. B.; BHARGAVA B. S. Preliminary nutrient norms for "Alphonso" mango using diagnosis and recommendation integrated system. Indian Journal of Agricultural Science, v. 69, p. 648-650, 1999.

RAGHUPATHI, H.B.; REDDY, B.M.; Srinivas. Multivariate diagnosis of nutrient imbalance in banana. Communications in Soil Science and Plant Analysis, v. 33, n. 13/14, p. 2131-2143, 2002.

REUTER, D.; ROBINSON, J. Plant Analysis. Melbourne, Sydney:Inkata press, 1988. $217 \mathrm{p}$.

REIS, R.A. dos. DRIS norms universality in the corn crop. Communications in Soil Science and Plant Analysis, v. 33, n. 5/6, p. 711-735, 2002.

RIGHETTI, T. L.; ALKOSHAB, O.; WILDER, K. Diagnostic biases in DRIS evaluations in sweet cherry and hazelnut. Communications in Soil Science and Plant Analysis, v. 19, p. 1429-1447, 1988a. 
RIGHETTI, T. L.; ALKOSHAB, O; WILDER, K. Verifying critical values from DRIS norms. Communications in Soil Science and Plant Analysis, v. 19, p. 1449-1466, $1988 b$.

RODRÍGUEZ, G. M. Estudios preliminares sobre nutrición con potasio de los bananos de América Central. Fruits, v. 35, n. 5, p. 283-291, 1980.

RODRÍGUEZ, O.; ROJAS E.; SUMNER, M. E Valencia orange DRIS norms for Venezuela. Communications in Soil Science and Plant Analysis, v. 28, p. 14611468, 1997.

RODRÍGUEZ, V.; RODRÍGUEZ, O. Normas foliares DRIS para el diagnóstico nutricional del plátano (Musa AAB subgrupo plátano cv. Hartón). Revista de la Facultad de Agronomía, LUZ, v. 14, p. 285-296, 1997.

RODRÍGUEZ, V.; BAUTISTA, D.; RODRÍGUEZ, O.; DÍAZ, L. Relación entre el balance nutricional y la biometría del plátano (Musa AAB subgrupo plátano $c v$. Hartón) y su efecto sobre el rendimiento. Revista de la Facultad de Agronomía, LUZ, v. 16, p. 425-432, 1999.

ROSSI, N. Nutritional status of high yield corn. In: INTERNATIONAL COLLOQUIM ON THE CONTROL OF PLANT NUTRITION, 4., Gent, 1976. Proceeding 4., International Colloquium on the Control of Plant Nutrition. Gent: A. Cottenie, 1976. v. 2. p.521-530..

SANZ, M. Evaluation of interpretation of DRIS system during growing season of the Peach tree: Comparison with DOP metod. Communications in Soil Science and Plant Analysis, v. 30, n. 7/8, p. 1925-1036, 1999. 
SAVOY, H.; ROBINSON, D. Norm range size effects in Calculating Diagnosis and Recomendation Integrated System Indices. Agronomy Journal, v. 82, p. 592-596, 1990.

SHAPIRO, S. S.; WILK, M. B. An analysis of variance test for normality (Complete samples). Biometrica, v.52, n. 2/3, p. 591-611, 1965.

SINGH, N.P.; AWASTHI, R.P.; SUD, A. Diagnosis and recommendation integrated system (DRIS) norms for apple (Malus $x$ Domestica Borkh. L. Cv. Starking Delicius) in imachal Pradesh. The Indian Journal of Horticulture, v. 3, p. 196204, 2000.

SCHALLER, H.; LÖHNERTZ, O; MICHEL, H. Improvements of the DRIS system and firsts experiences in grapevine nutrition with special consideration of the compositional nutrient diagnosis approach. Acta Horticulturae, v. 383, p.171-189, 1995.

SUMNER, M. E. Aplications of Beaufils diagnostics indices to maize data published in the literature irrespective of age and conditions. Plant and Soil, v. 46, p. 359-369, 1977a.

SUMNER, M. E. Preliminary N, P and $\mathrm{K}$ foliar diagnosis norms for soybean. Agronomy Journal, v. 69, p. 226-230, 1977b.

SUMNER, M. E. Effect of corn leaf sampled on $\mathrm{N}, \mathrm{P}, \mathrm{K}, \mathrm{Ca}$ and $\mathrm{Mg}$ content on calculated DRIS indices. Communications in Soil Science and Plant Analysis, v. 8 , p. $269-280,1977$ c. 
SUMNER, M.E. Use of the DRIS systems in foliar diagnosis of crops at high yields levels. Comunications in Soil Science and Plant Analysis, v. 8, n. 3, p. 251-268, 1977d.

SUMNER, M. The use and misuse of the Diagnosis and Recommendation Integrated System (DRIS) in foliar diagnosis. (compact disc). In: SIMPÓSIO SOBRE MONITORAMENTO NUTRICIONAL PARA A RECOMENDAÇÃO DA ADUBAÇÃO DE CULTURAS, Piracicaba, 1999 Anais. Piracicaba:POTAFOS/PPI, 1999.

SZCÜCS, E.; KÁLLAY, T.; SZENCI, G. Determination of DRIS indices for Apple (Malus domestica Borkh). Acta Horticulturae, v. 274, p.443-447, 1990.

SZCÜCS, E.; KÁLLAY, T. Determination of fruiting capacity of apple trees (Malus domestica) by DRIS. IN: PLANT NUTRITION-PHYSIOLOGY AND APPLICATION, Nertherlands, 1990. Plant Nutrition-Physiology and Application. Nertherlands:Kluwer Academic , p. 717-721, 1990.

TWYFORD, I. T.; COULTER, J. K. Foliar diagnosis in banana fertiliser trials. In: COLOQUIUM PLANT ANALYSIS AND FERTILIZER PROBLEMS, 4., Brussels, 1962. Plant Analysis and Fertilizer Problems. New York:W. F. Humphrey Press, 1964. v. 4, p. 357-370.

TWYFORD, I.T.; WALMSLEY, D. The mineral composition of the robusta banana plant. Plant and Soil, v. 39, p. 227-243, 1973.

ULRICH, A. Physiological bases for assessing the nutritional requirements of plants. Annais Review of plant physiology, v. 3, p. 207-228, 1952. 
WADT, P.; NOVAIS, R.; ALVAREZ V.; FONSECA, S.; BARROS, N.; DIAS L. Três métodos de cálculo do DRIS para avaliar o potencial de resposta à adubação de arvores de eucalipto. Revista Brasileira da Ciencia do Solo, v. 22, p. 661-666, $1998 \mathrm{a}$.

WADT, P.; NOVAIS, R.; ALVAREZ V.; FONSECA, S.; BARROS, N. Valores de referencia para macronutrientes em eucalipto obtidos pelos métodos DRIS e chance matemática. Revista Brasileira da Ciencia do Solo, v. 22, p. 685-692, 1998 b.

WADT, P. G. S; NOVAIS, R. F DE; VENEGAS, V. H. A; BRAGANÇA, S. M. Alternativa de aplicação do DRIS à cultura de Café Conilon (Coffea canephora Pierre). Scientia Agrícola, v.56, n. 1, p. 83-92, 1999.

WALWORTH, J.; SUMNER, M. E. The Diagnosis and Recommendation Integrated System (DRIS). Advanced in Soil Science, v. 6, p. 149-188, 1987.

WARNER, R.M.; FOX, L.M. Nitrogen and Potassium Nutrition of Giant Cavendish Banana in Hawaii. Journal of the American Society for Horticultural Science, v.102, n. 6, p.739-743, 1977.

WOOD, J. The mathematical expression of crop response to inputs. In: COLLOQUIUM OF THE INTERNATINAL POTASH INSTITUTE, 15., Wageningen, 1980. Physiological Aspects of Crops Productivity. Bern:Der Bund AG, 1980. p. $263-270$.

WORTMANN, C.; KISAKYE, J.; EDJE, O. The diagnosis and recommendaton integrated system for dry bean-determination and validation of norms. Journal of Plant Nutrition, v. 15, p. 2369-2379, 1992. 
ANEXO 


\section{ANEXO A}

Numero de amostras e localização relativa das lavouras amostradas.

\begin{tabular}{lccc}
\hline Lavoura $(*)$ & 1er amostragem & 2do amostragem & Localização \\
\hline Trinidad & ----- & 39 & $0982843 \mathrm{~N}$ \\
& 42 & 34 & $209284 \mathrm{E}$ \\
Janeiro & 46 & 42 & $0978199 \mathrm{~N}$ \\
Bella Vista & & & $203804 \mathrm{E}$ \\
& 18 & $33(* *)$ & $0989514 \mathrm{~N}$ \\
Fortuna & & & $208277 \mathrm{E}$
\end{tabular}

(*)Plano de adubação: $200 \mathrm{~g}$ sulfato de amônio $200 \mathrm{~g} 12-12-17 / 2$

(**) Roubadas todas. Nas restantes lavouras e amostragem, perderão-se o $39 \%$, principalmente por chuvas torrenciais no segundo amostragem. 